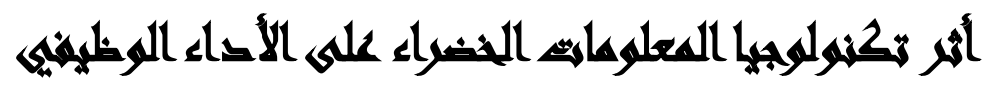

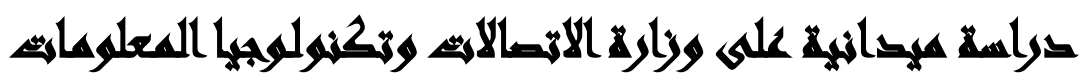

\author{
وليد محمد عبد الحفيظ(')- ممدوح عبد العزيز رفاعي(ץ)- محمد حسن عبد العزيز(r)(

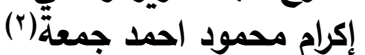

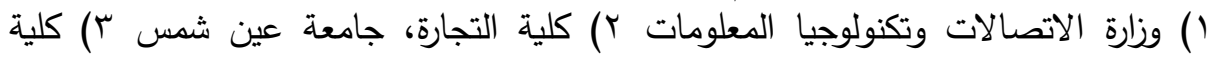

الحاسبات والمعلومات، جامعة عين شمس الاتص ونعات

\section{(T)}

تهدف الدراسة الحاليـة إلى معرفة آثر تكنولوجيا المعلومات الخضراء على رفع كفاءة

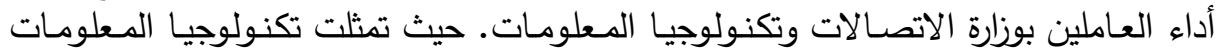

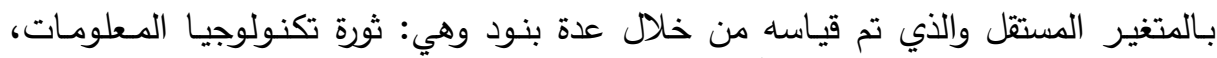

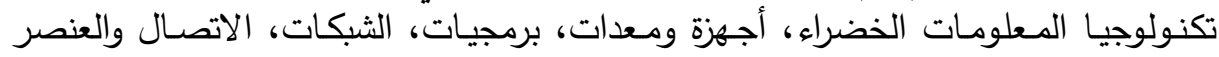

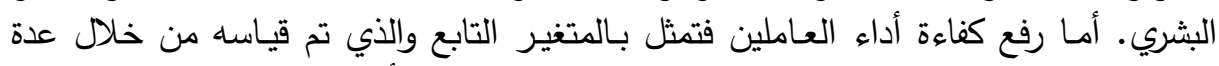

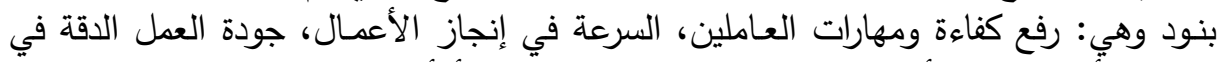

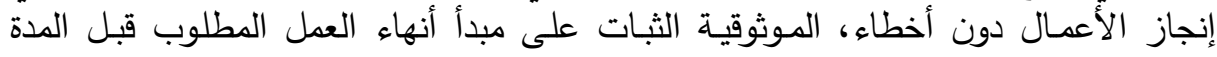

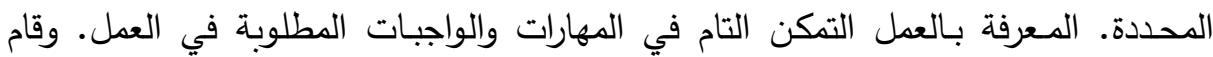

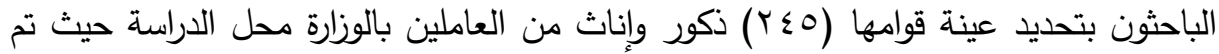

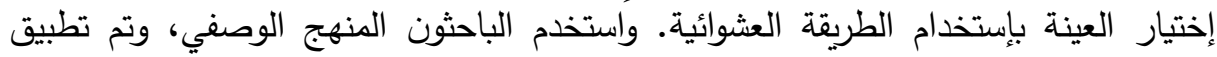

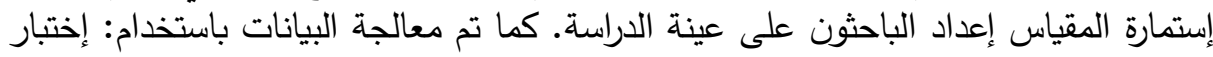

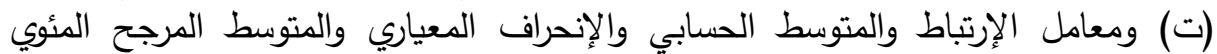
والأعداد والنسب لكل أسئلة المقياس.

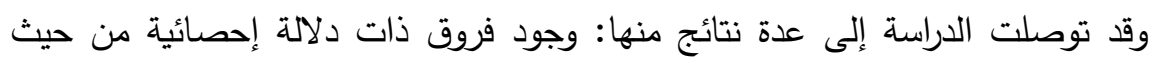

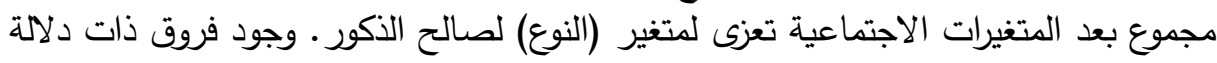

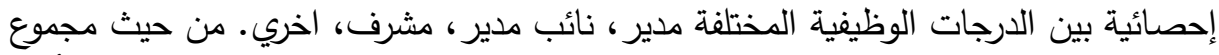

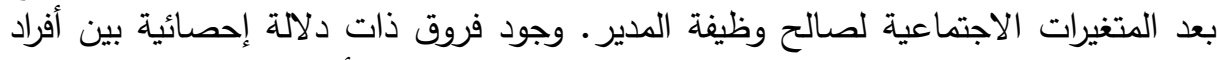

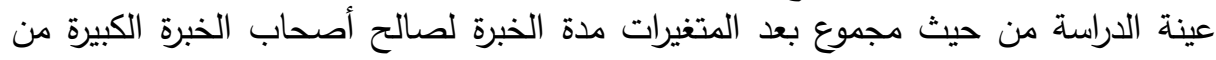

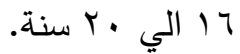


توصيات الدراسة: متابعة ومواكبة التطورات العالمية للتكنولوجيا وتتفيذ اعمالها وتطبيقها

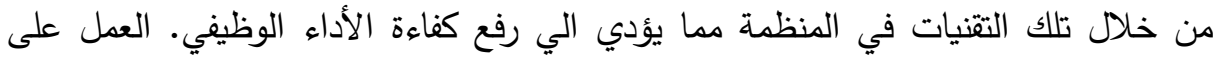
توفير برمجيات تتناسب مع تتفيذ المهام المطلوبة بسهولة وتطبيقها عمليا على جميع المئ الادارات.

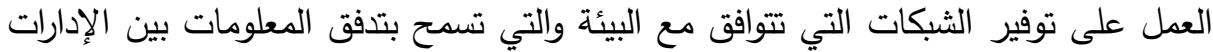

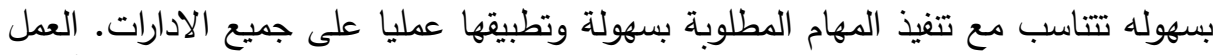

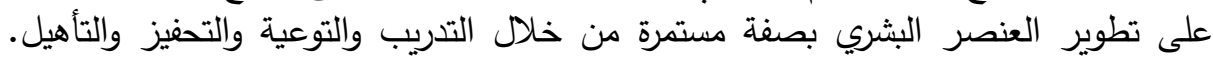

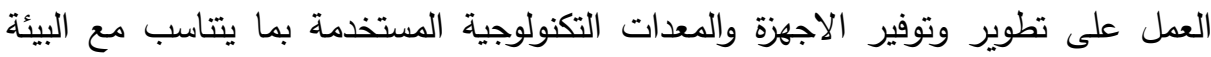
والاعمال المطلوب إنجازها وصيانتها وتدريب العاملين عليها.

\section{And xasa}

تشهد الجهات الحكومية منذ تسعينيات القرن الماضي إهتمامـا متزايدا بدراسة أفضل

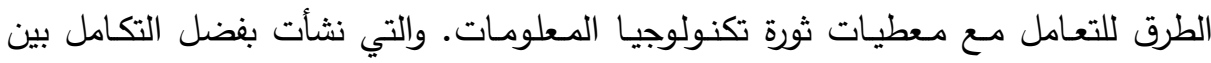
حصيلة المعارف التي توصل إليها العالم والتطور الملحوظ في تكنولوجيا لتونيا الاتصـالات والتطور المتلاحق في صناعة أجهزة الحاسب الآلي. حتى أصبح من نتائج تلك التطورات

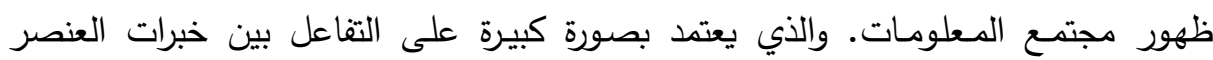

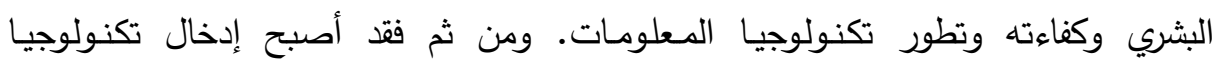

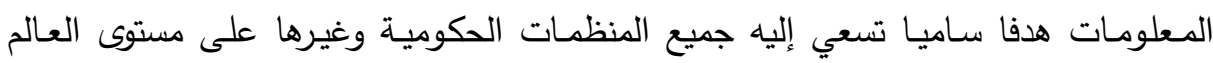

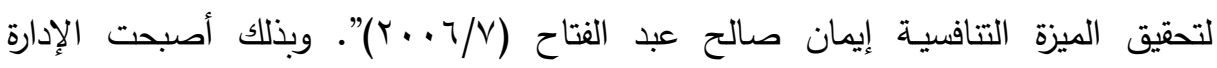
الإلكترونيـة ضرورة حتمية لكل منظمة تسعى إلى التقدم وتواكب التطورات العالميـة وصولا إلى التطبيق الفعلي للتكنولوجيا الخضراء. والتي تعتبر الامتداد الطبيعي والفعلي لتطور تكنولوجيا المعلومات التطور السليم والتي بدورها تؤدي إلى الاعتمـاد على تبلى تبادل

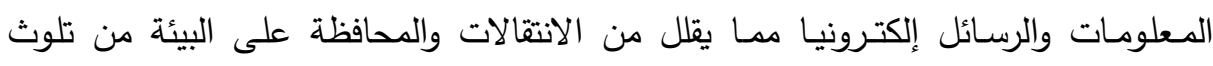

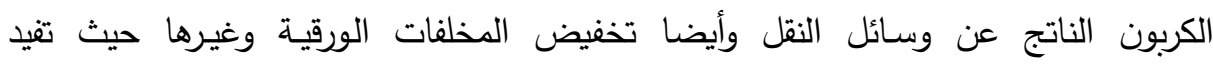
تكنولوجيا المعلومات الخضراء البيئة بتحسين كفاءة الطاقة، تخفيض الغازات الدفيئة، استخدام مواد أقل ضررا، وتثجيع إعـادة الاستخدام وإعادة التدوير • وهكذا فإن تكنولوجيا 576

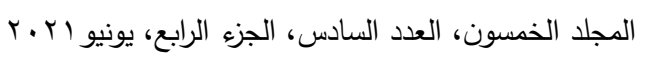

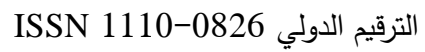


المعطومات الخضراء تثمل كحلاً من أبعاد الاستدامة البيئية، واقتصـاديات استخدام الطاقة،

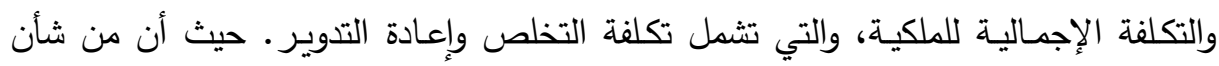

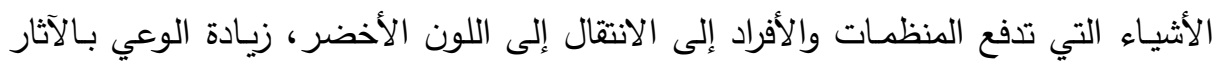

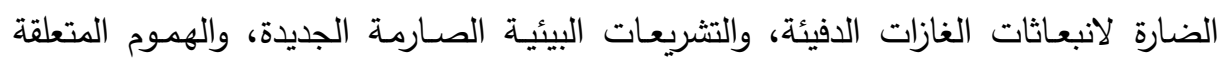
بالممارسات الإلكترونيـة للتخلص من النفايات، وكل ما يتعلق بـالمحافظة على الصورة المؤسسية. وبعبارة أفضل (عدم التخلف عن نهضة التقدم والمعرفة). وقد ترتب على تلك التحولات أنه أصبح من الضروري إعادة توصيف قدرات العاملين

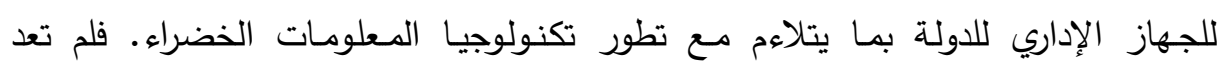

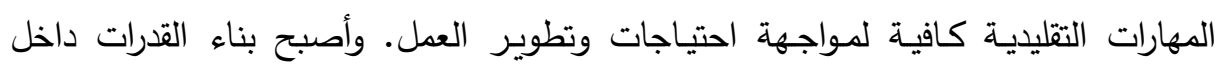

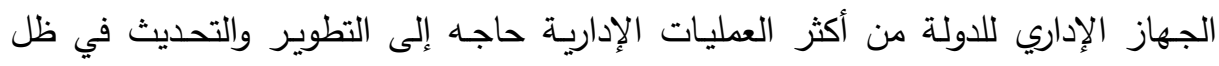

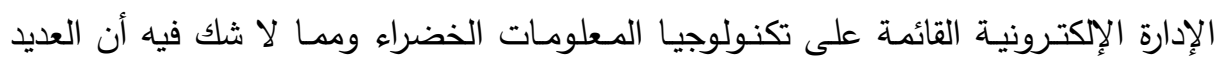

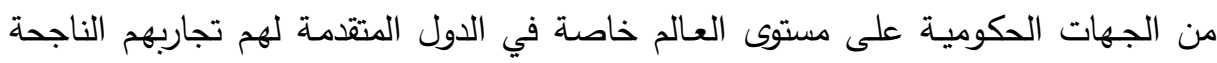
في تطوير قدرات العاملين لديها Washington, D.C. 2003, P.1 وفي إيجاد منظومة لئه جديدة لبناء قدراتهم بما يتلاءم مـع تطور تكنولوجيا المعلومات ومـا توصلت إليه من أفكار

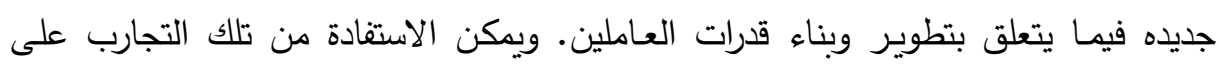
مستوى الجهاز الإداري للحكومـة المصريـة.

\section{And Xilin}

في إطار تحديد وصياغة مشكلة الدراسة وتكوين الفروض؛ قام الباحثون بدراسة

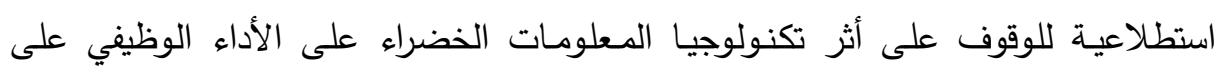

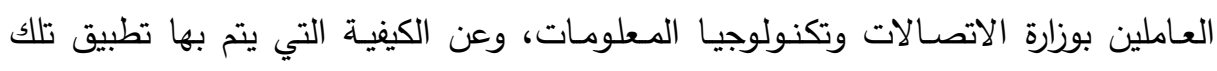
التكنولوجيا، بـالإضافة إلى تكوين فكرة مبدئية عن مشكلة الدراسة، وتحديد متغيراته

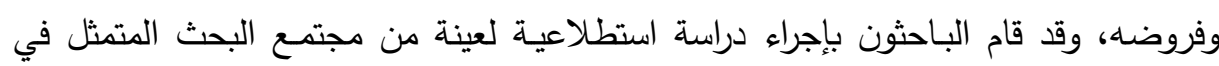

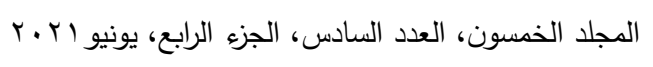


وزارة الاتصـالات وتكنولوجيا المعلومات عن طريق عقد عدة مقابـلات شخصيـة منظمة ومحددة خلال شهر مارس • r.r. . وتبين أن هناك فجوه كبيرة بين التطور السريع للتكنولوجيا وبين ألية وبيئة العمل حيث تطورت تكنولوجيا المعلومات والاتصـالات بصورة سريعة ومتزايدة مما أنشأ علاقة وثيقة بين تطور تكنولوجيا المعلومات وتطوير المهارات الفنيـة

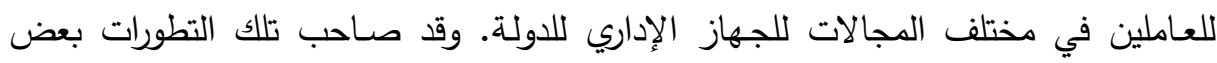
الآثار السلبية على الإدارة العامة والقدرات البشريـة. مثل التأثثر على البيئة وبالتالي كفاءة لإداء

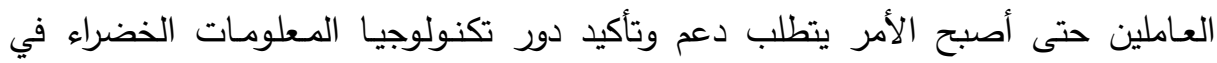

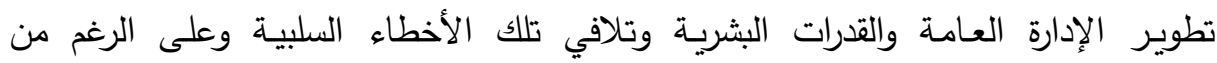

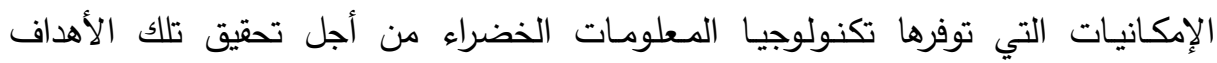

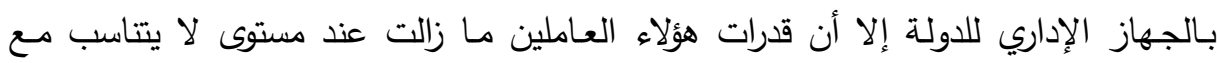

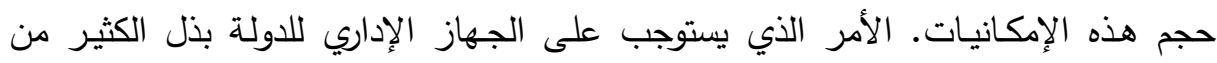

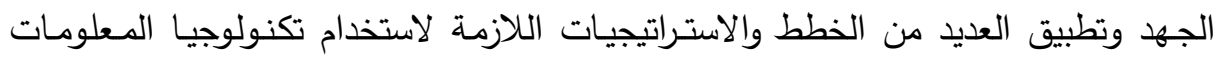

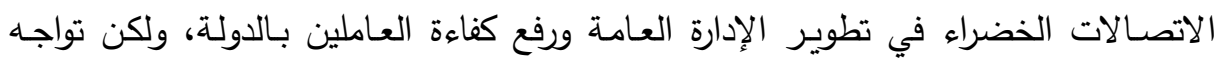
هذه الجهود والخطط صعوبات وعقبات في سبيل تحقيق الأهداف المنشودة. ومن ثم فأن هذا البحث يقوم على إعادة النظر في نظام الإدارة العامة وبناء قدرات العاملين بما يتلاءم مـع تكنولوجيا المعلومـات الخضراء.

\section{تمساؤلايت اللهمبه}

• إلى أي مدى يوجد فرق بين تكنولوجيا المعلومـات وتكنولوجيا المعلومـات الخضراء؟ • • ما العلاقة تأثيريـة لتكنولوجيا المعلومـات الخضراء على على الأداء الوظيفي للعاملين؟

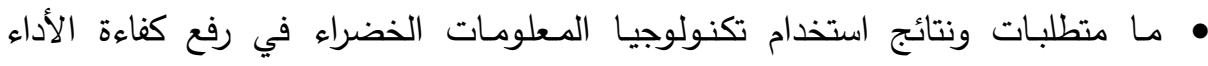
الوظيفي للعاملين بالجهاز الإداري بالدولة؟ 


$$
\begin{aligned}
& \text { مجلة العلوم البيئية } \\
& \text { معهد الدراسات والبحوث البيئية - جامعة عين شمس لئن } \\
& \text { وليد محمد عبد الحفيظ وآخرون }
\end{aligned}
$$

• إلى أي مدى نجحت تجربة الجهاز الإداري للدولة في استخدام تكنولوجيا المعلومات

$$
\text { الخضراء؟ }
$$

• ما الدلالات التي تؤكد التطبيق الفعلي للتكنولوجيا الخضراء عند استخدام تكنولوجيا

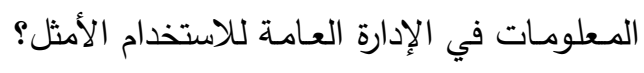

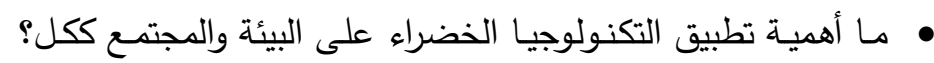

\section{أهسا اهثم المهمه}

• الكثف عن طبيعة تأثير تكنولوجيا المعلومات الخضراء في الأداء الوظيفي للعاملين

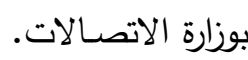

ه إلقاء الضوء على أحدث الطرق والأسـاليب لتطوير الإدارة العامة في ظل تكنولوجيا المعلومات الخضراء.

• تطبيق إمكانيات تكنولوجيا المعلومات الاتصـالات في رفع كفاءة الأداء الوظيفي

$$
\text { للعاملين بالجهاز الإداري في الدولة. }
$$

• استخدام تكنولوجيا المعلومـات كوسيلة لتطبيق التكنولوجيا الخضراء في الدولة.

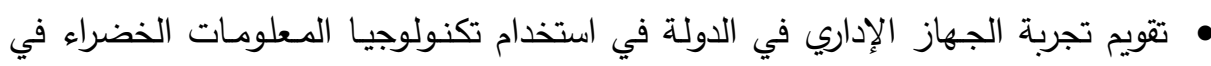
تطوير الجهاز الإداري.

\section{أهمية المهيث}

الأهميـة العلميـة: برغم توافر العديد من الدراسـات السـابقة التي تتاولت موضوع البحث وهو

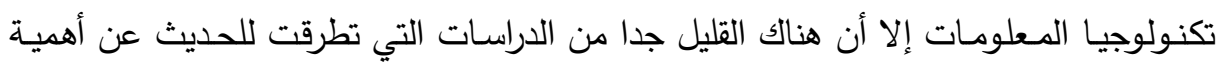

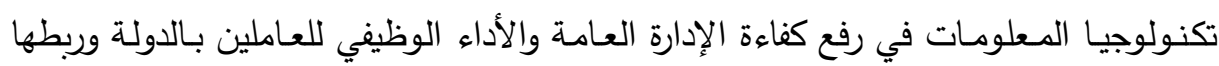
بتطبيق التكنولوجيا الخضراء.

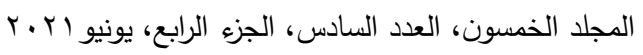

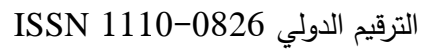


كما ترجع أهميـة البحث في تتاوله لأحد الموضوعات التي اكتسبت المزيد من الأهميـة في ظل تكنولوجيا المعلومات وتغيير دور الدولة وهو رفع كفاءة الإدارة العامة والأداء الوظيفي للعاملين بالدولة وبتطبيق التكنولوجيا الخضراء.

وممـا يؤكد على أهميـة الدراسة العلميـة أنها لا تقتصر على على تأهيل الكوادر الحكوميـة في تكنولوجيا المعلومات عن طريق التدريب والتعليم وحسب بل تتتاول موضوع رفع كفاءة

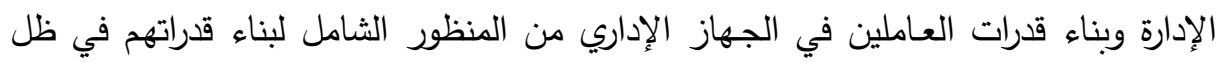

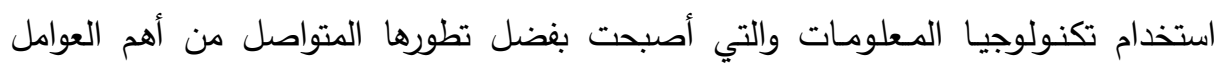
المؤثرة على المنظمة ككل.

الأهميـة التطبيقيـة: أي أهميـة وزارة اتصـالات وتكنولوجيا المعلومـات حيث أنها الجهة

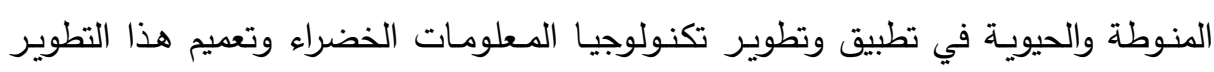

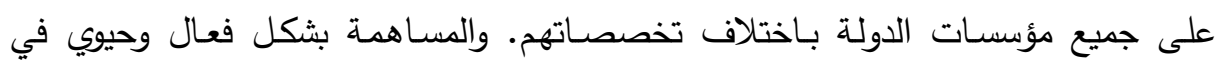
التحول الرقمي على مستوى مؤسسات الدولة. وخصوصـا ونحن في مرحلة جائحة كورونا

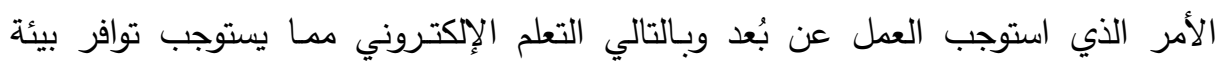

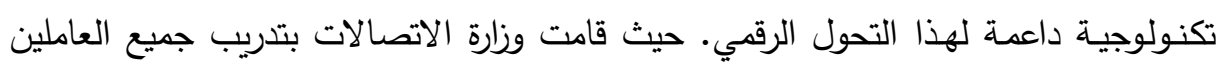
بالوزارات المختلفة على أساسيات التحول الرقمي والرقمنه. وتسـاعد هذه الدراسة على تطوير الإدارة العامة وبناء قدرات العاملين بـالجهاز الإداري

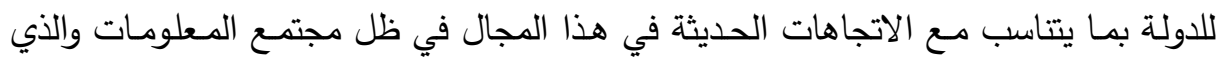

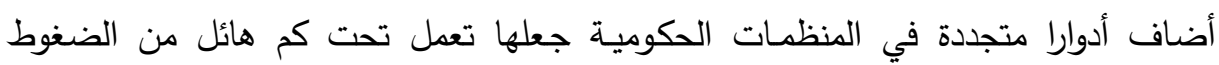
الداخلية والخارجيـة.

كما تساعد الدراسة في أن تجعل المنظمات الحكوميـة أكثر قدرة على اتخاذ القرارات المناسبة في وقت أسرع وبقدرة كبيرة. 


$$
\begin{aligned}
& \text { مجلة العلوم البيئية } \\
& \text { معهد الدراسات والبحوث البيئية - جامعة عين شمس له } \\
& \text { وليد محمد عبد الحفيظ وآخرون }
\end{aligned}
$$

وتسـاعد الدراسة في تطوير العلاقة بين جميع أجهزة الدولة شكلا ومضمونا داخل إطار

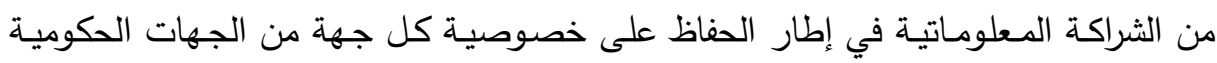
للحصول على أفضل النتائج والخدمات.

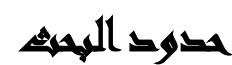

تحددت مجالات الدراسة (الدكاني، الموضوعي، الزمنى، البشري) وذلك على النحو التالي:

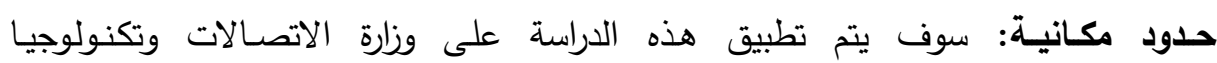
المعلومات. حدود مـوضوعيـة: تركز الدراسة بصفة أسـاسية على متغيرين هــا: تكنولوجيا المعلومات

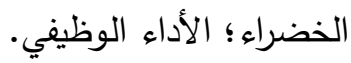

تتعدد أبعاد وعوامل تكنولوجيا المعلومات الخضراء، وقد اقتصرت الدراسة على تتاول

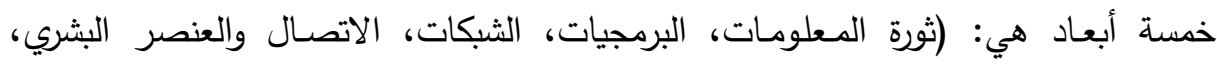
أجهزة ومعدات).

بينما تقتصر الدراسة الحالية على أبعاد الأداء الوظيفي من حيث رفع كفاءة ومهارات

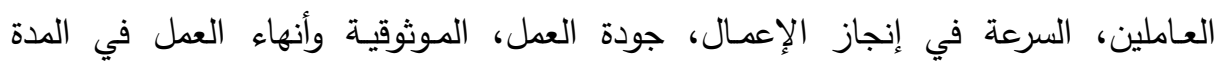
المحددة، المعرفة بالعمل والتمكن في المهارات والواجبات.

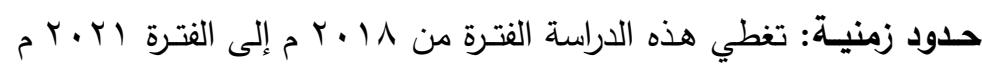

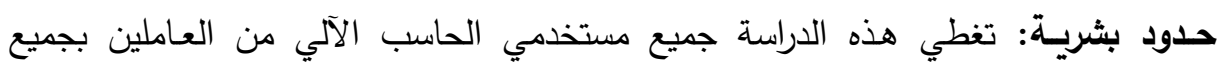
الإدارات العليا والوسطى والتتفيذيـة من قيادات وموظفين بـالوزارة بوزارمحل الدراسة.

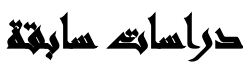

قام الباحثون بعرض أهم الدراسات السابقة التي تتاولت أثر تكنولوجيا المعلومات على الأداء

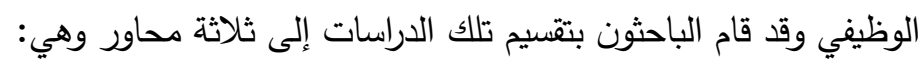

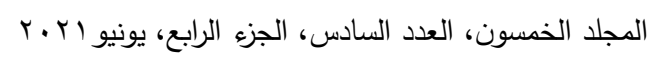


الدراسات التي تتاولت تكنولوجيا المعلومات. الدراسات التي تتاولت الأداء الوظيفي.

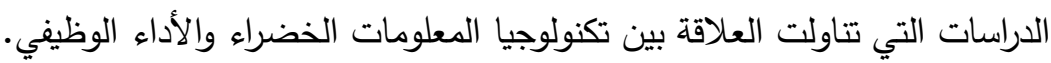
الدراسات التي تتاولت تكنولوجيا المعلومات.

Butler \& Chen (2011): Exploration of sustainable development by applying green economy indicators.

بعنوان "استكثاف التتميـة المستدامة من خلال تطبيق مؤشرات الاقتصـاد الأخضر"

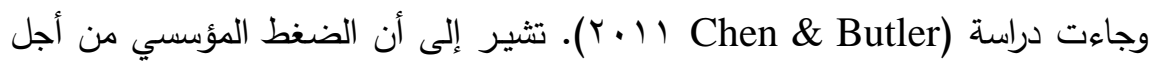

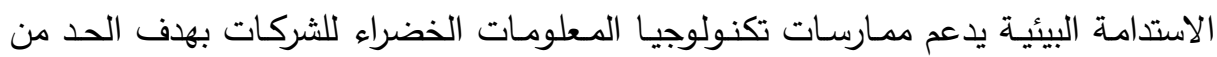
الانبعاثات الكلية والنفايـات الإجمالية والاستخدام الكلي للمواد الخطرة والسامة بالتفصيل.

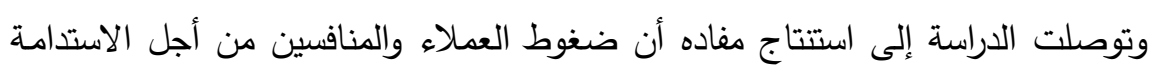

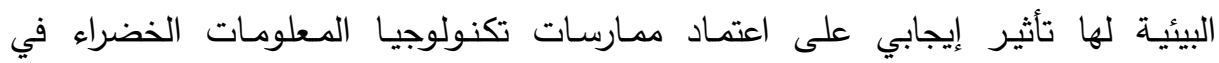

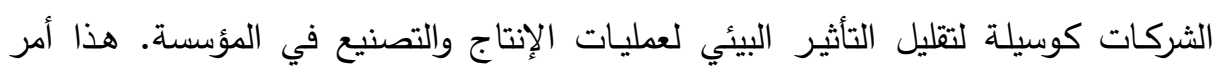

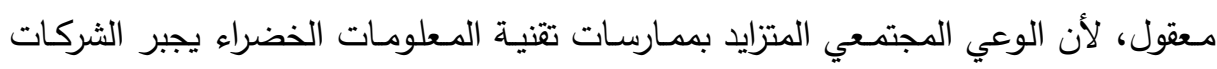

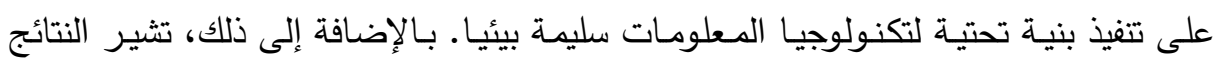

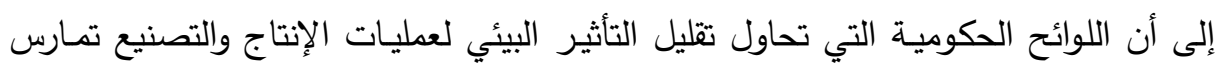
ضغطًا على الثركات لتبني مدارسات تكنولوجيا المعلومـات الخضراء. (Lewin, 2017) دراسة

A New Culture Of Learning: Developing Computing In The Curriculum And Advancing Digital Pedagogy

$$
\text { بعنوان: ثقافة جديدة للتعلم: تطوير الحوسبة في المناهج الدراسية والتقدم الرقمي. }
$$

تستتد الدراسة إلى إطار عمل محدد حيث تتأثر محو الأميـة الحاسوبية والمعلومـاتيـة

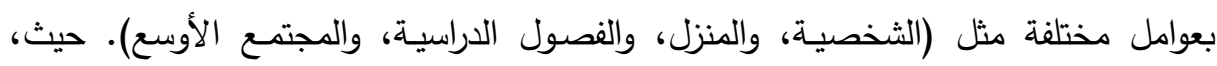
يجب أن تتضمن عمليـة التدريس على تكنولوجيا المعلومـات الاتصـالات وبالتالي استخدام 
تكنولوجيا المعلومـات الاتصـالات داخل الصف. وبالتالي يجب تطوير خصـائص المدارس

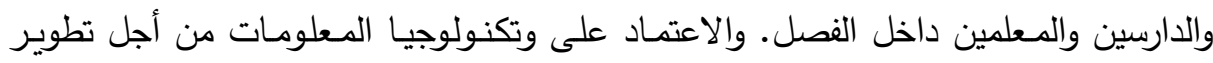
الحوسبة في التعليم والتقدم الرقمي.

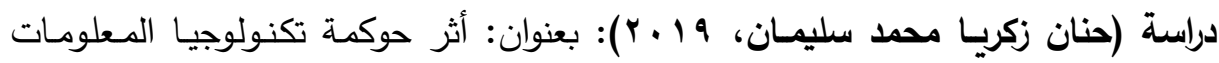
على جودة التقارير المالية. تمثل الهدف الرئيسي للبحث في التعرف على أثر تطبيق آليات حوكمة تكنولوجيا

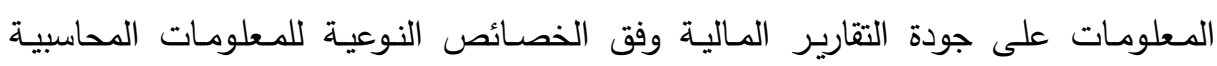

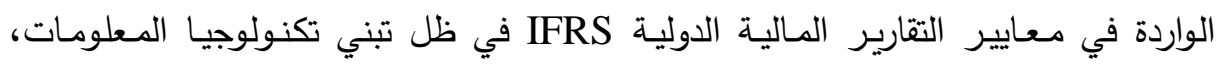
ويتم تحقيق ذلك الهدف من خلال مجموعة من الأهداف الفرعية.

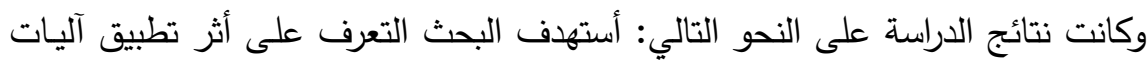

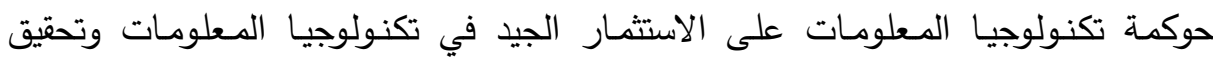

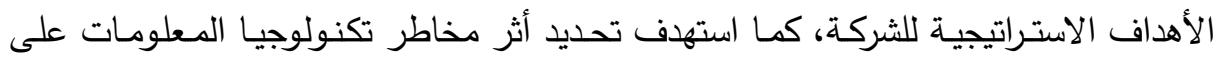

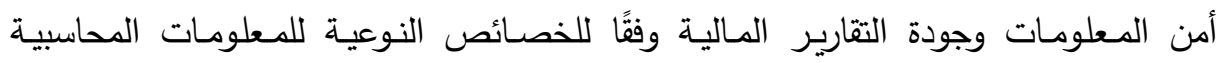
الواردة في معايير التقارير الماليـة، كما استهدف التعرف على أثر تطبيق معايير حوكمة وهما

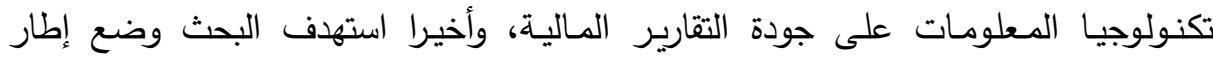
مقترح لتفعيل حوكمة تكنولوجيا المعلومـات لتحقيق جودة التقارير المـاليـة.

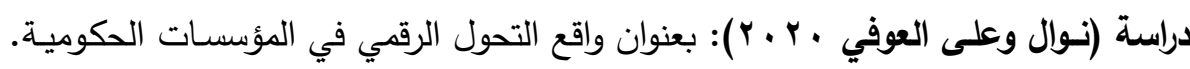

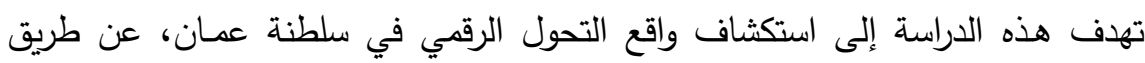
التعرف على الأدوار التي تقوم بها المؤسسات المختلفة بالسلطنة في مجال التحول الرقمي

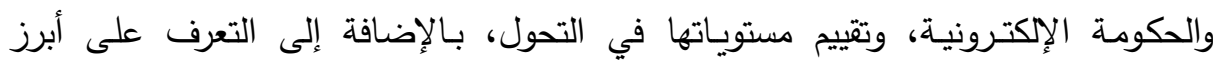
المشاريع المنفذة بها في هذا الجانب، تمـاشيا مـع التوجهات العالمية في المجال.

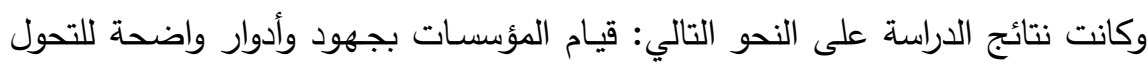
رقميا، من توعية وتثقيف وتدريب وتكامل وجاهزيـة وغيرها، كما تفاوت مستوى التحول

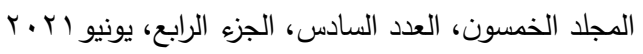

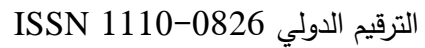


بالمؤسسات عينة الدراسة إلا أن جميعها بذلت جهودًا ساعدت في تقدّم المؤسسات بالسلطنة في مستوى التحوّل الرقمي وارتقاع مستواها في مجالات التقييم الأخرى كالمشاركة الإلكترونيـة. وتمثلت أبرز مشاريع التحوّل بالسلطنة في مشاريع البنيـة الأساسيـة كنظام

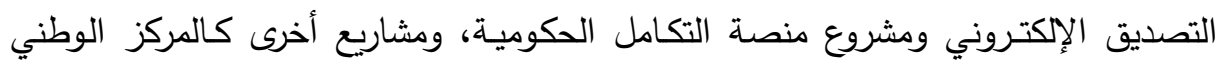
للسلامـة المعلوماتيـة، ومراكز سـاس المختلفة بوزارة التقنية الاتصـالات.

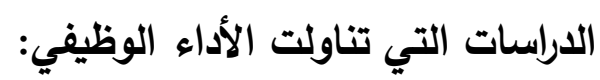
دراسة (العوضي، ^ . . ץ): بعنوان أثر الحكومة الإلكترونية على الجودة الثاملة والأداء الوظيفي.

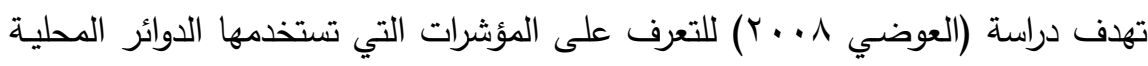

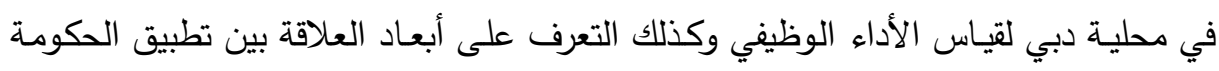
الإلكترونيـة وإدارة الجودة.

وكانت نتائج الدراسة على النحو التالي: تعارض وتداخل الاختصـاصـات بين الوحدات

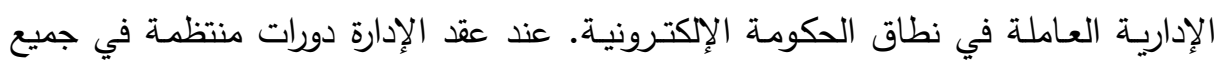
التخصصـات الإلكترونية للعاملين في الإدارة وفي جميع المستويـات الإداريـة الإدية أن النظام الحالي لا يعمل على تتميـة الروح المعنوية للعاملين وتطوير أدائهم. لا يتم

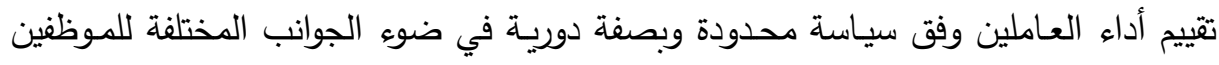
ومتطلبات الحكومة الإكترونيـة.

(Mayfield, 2010) دراسة

"in flounce on motivation language a two levels model innovation on work performance"

$$
\text { بعنوان "أثر الالتزام الوظيفي على مستوى كفاءة العاملين والرضا الوظيفي" }
$$


وفي نفس المجال وفي الولايات المتحدة قام (Mayfield, 2010) بتوسعة نطاق نظريـة التحفيز وذلك ببحث دور الالتزام الوظيفي على مستوى أداء الموظفين والرضا الوظيفي.

وقد انتهت هذه الرسـالة إلى أن مهارات القائد في اللغة التحفيزيـة تؤثر على العلاقات

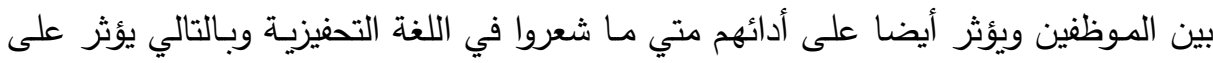
رضاهم الوظيفي.

دراسة (وسـام على حسين، 17 1 ب): بعنوان تكنولوجيا المعلومات ودورها في تحسين الأداء الوظيفي.

تتجسد أهمية البحث في تتاولها متغيرين (تكنولوجيا المعلومـات وتحسين الأداء الوظيفي يعد جانب ذو أهميـة كبيرة كونه ترتبط بالتطورات الحاصلة على مستوى الجامعات

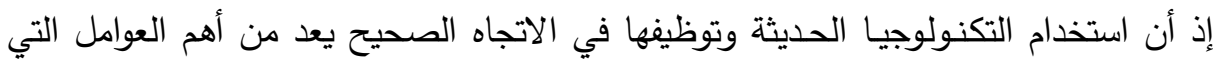
يمكن من خلالها مواكبة التغييرات المتسارعة في بيئة عمل المنظمات.

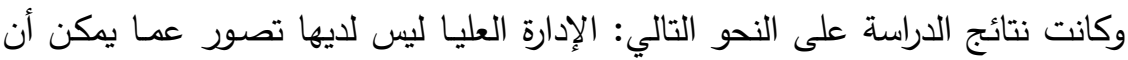

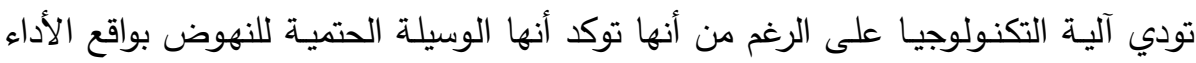

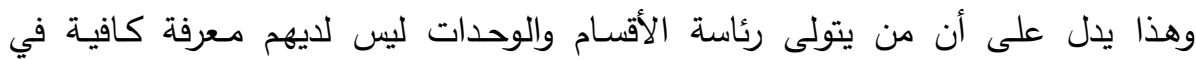

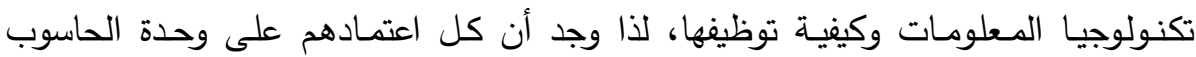
المركزيـة الموجودة في الجامعة. الدراسات التي تناولت العلاقة بين تكنولوجيا المعلومات الأداء الوظيفي: :Huang, 2007)

"The Effect of Investment in Information Technology on the Performance"

بعنوان: أثر الاستخدام الفعال لتكنولوجيا المعلومـات على الأداء الوظيفي للعاملين.

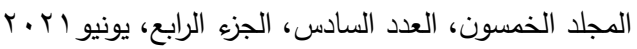

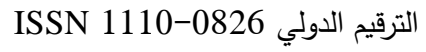


هدفت هذه الدراسة إلى التعرف على أثر الاستثمار في تكنولوجيا المعلومات على أداء

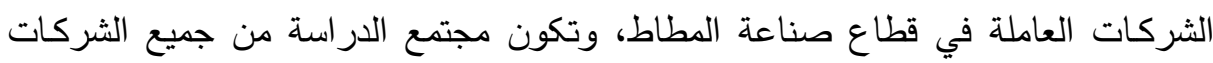
العاملة في صناعة المطاط في تايوان، ولتحقيق هدف الدراسة إستخدم الباحثون المنهج

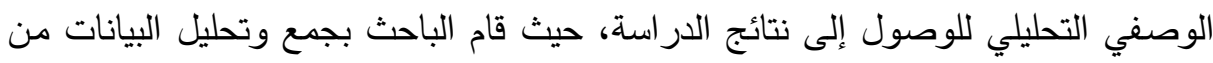

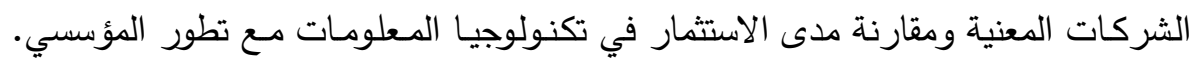

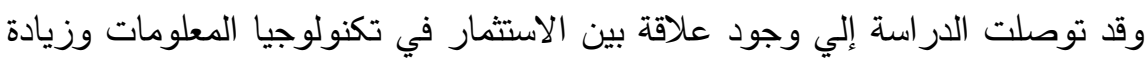

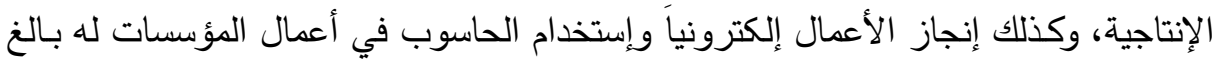

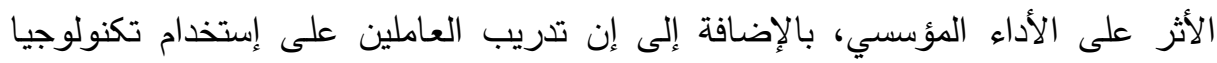

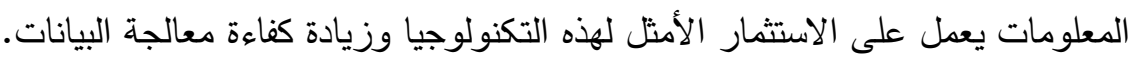
دراسة (متولي، • • ب): بعنوان دور تكنولوجيا المعلومات في تطوير أداء العاملين بالأجهزة الحكومية. وامتدادا لما سبق هدفت دراسة (متولي • • ب) إلى تقويم دور تكنولوجيا المعلومات في تطوير أداء العاملين بـالأجهزة الحكوميـة وذلك مـع التركيز على حالة كلية الاقتصـاد والعلوم السياسيـة - جامعة القاهرة وصولا إلى تحديد العقبات التي تواجـه الكليـة بغيـة الوصول في النهايـة إلى تطويـر الكليـة. وكانت نتائج الدراسة على النحو التالي: تثكل الدخدلات من موارد بشريـة ذات كفاءة

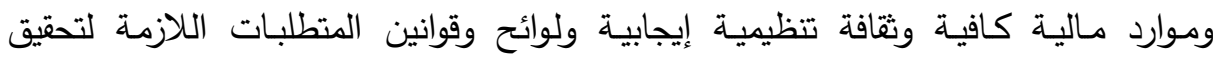
المخرجات المنشودة لاستخدام تكنولوجيا المعلومـات في تطوير أداء العاملين بـالأجهزة الحكومية. وهذا ويتحقق الدور المنشود لتكنولوجيا المعلومات في تطوير أداء العاملين بالأجهزة الحكوميـة في التجارب الناجحة وفقا لنموذج يقوم على مدخلات تتعلق بموارد

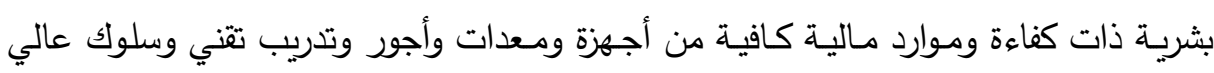
وكذلك ثقافة تنظيميـة إيجابيـة وأيضا لوائح وقوانين. 
دراسة (الديري، 11 1 ب): بعنوان أثر تكنولوجيا المعلومـات في بناء قدرات العاملين.

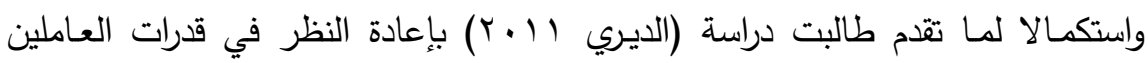

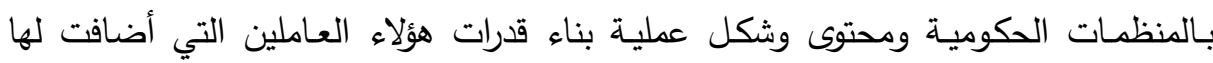
تكنولوجيا المعلومـات أبعاده جديدة حتى يمكن حتى يمكن تعظيم معدلات الاستفادة من تكنولوجيا المعلومات وإمكانيتها على صعيد بناء القدرات. وكانت نتائج الدراسة على النحو التالي: فيما عدا بعض المؤشرات الإيجابيـة توجد

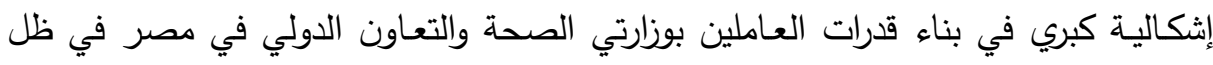
تكنولوجيا المعلومات ليس فقط بسبب انخفاض مستوى المؤشرات المطروحة من خلال هذه

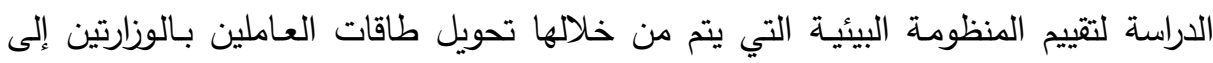

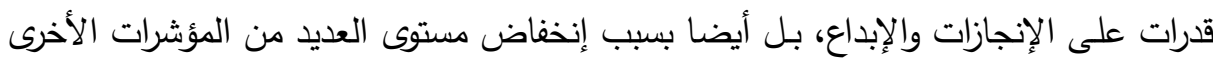
المطروحة لتقييم طاقات العاملين.

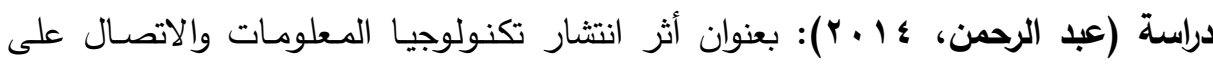
أداء الدنظمات. وفي نفس السياق ركزت دراسة (عبد الرحمن ؟ ( ب) على تأثير تكنولوجيا المعلومات

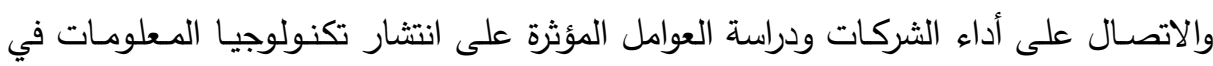
الاقتصـاد المصري على المستوى الكلي والجزئي من خلال مساهمته في نـو الناتج المحلي والإجمالي وإضافة فرص عمل. وكانت نتائج الدراسة على النحو التالي: هنالك تأثير إيجابي لتكنولوجيا المعلومات والاتصـال على أداء الشركات كما خلصت إلى وجود مجموعة من العوامل المؤثرة على لنى

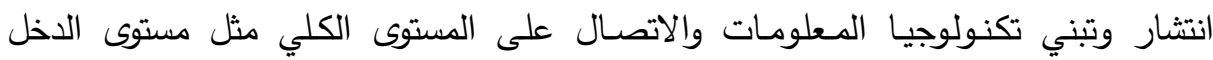

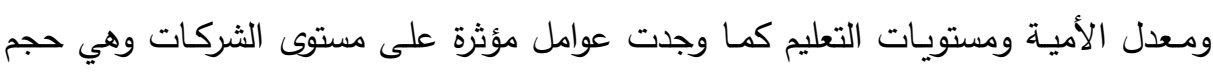
الشركـة وكفاءة الموارد البشريـة وتكاليف الاستثمـار . 


$$
\begin{aligned}
& \text { مجلة العلوم البيئية } \\
& \text { معهد الدراسات والبحوث البيئية - جامعة عين شمس لبنه } \\
& \text { وليد محمد عبد الحفيظ وآخرون }
\end{aligned}
$$

\begin{tabular}{|c|c|c|}
\hline ليه & بشية & سابقة \\
\hline 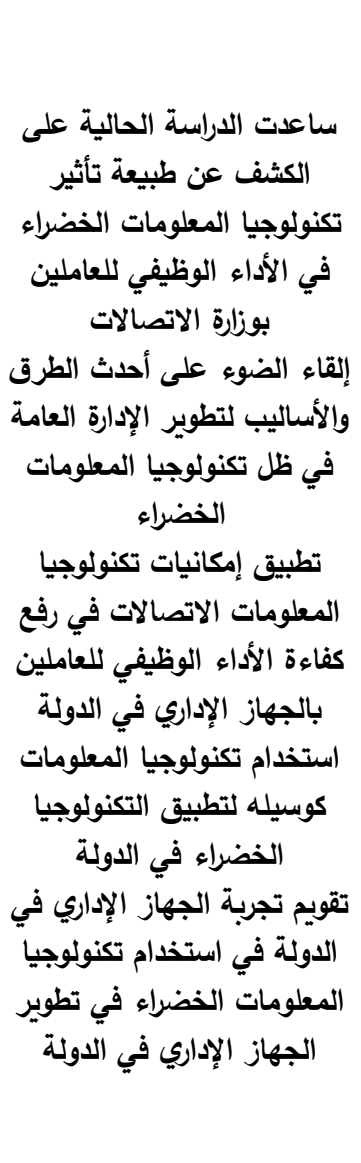 & 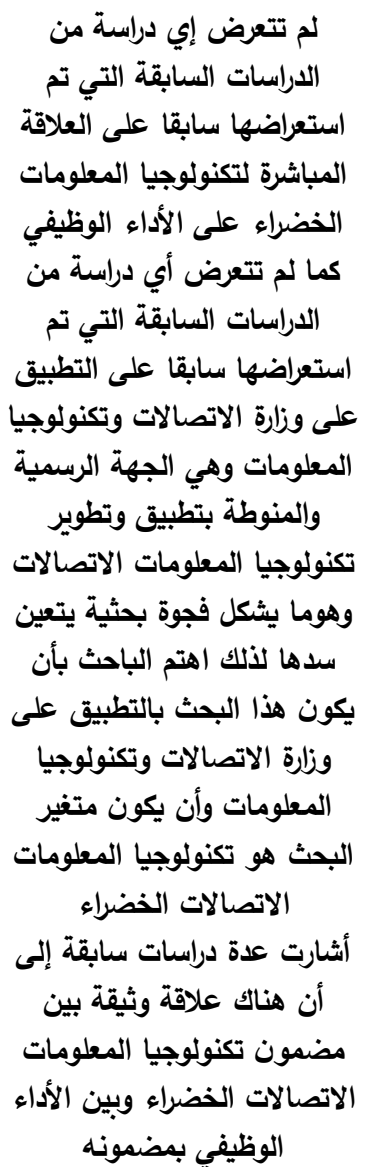 & 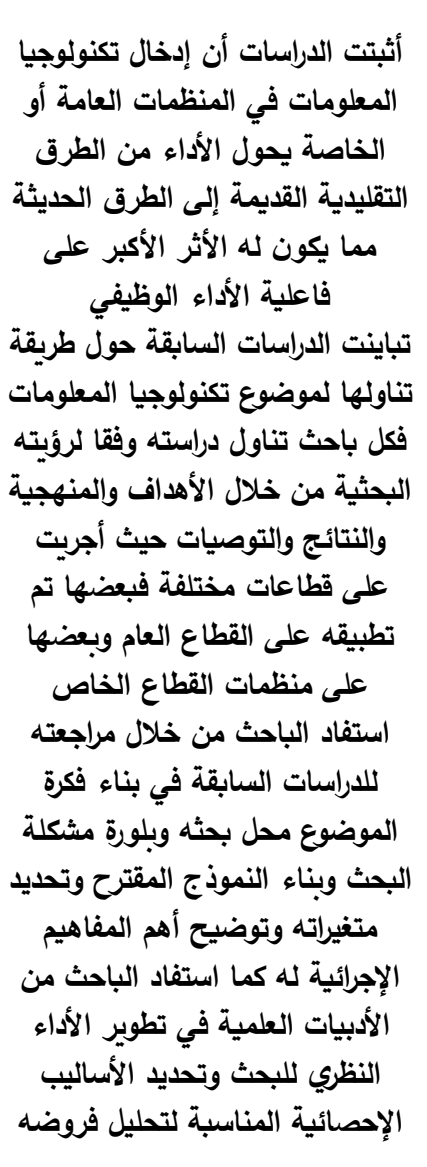 \\
\hline
\end{tabular}

التعليق على الاراسات السابقة وتحديد الفجوة البحثية: 


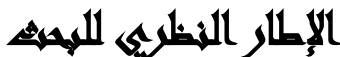

تعد تكنولوجيا المعلومات أحدي أهم العوامل المؤثرة في تطور مستوى المجتمعات ولقد أدى التطور الكبير في تكنولوجيا المعلومات خلال العقدين الماضيين إلى تغير جوهري في أنماط حياة الثعوب، من حيث أساليب الحياة، والتواصل الاجتماعي والحصول على المعلومات فنجد أن موضوع تكنولوجيا المعلومات حظي باهتمام العديد من الباحثين والدارسين

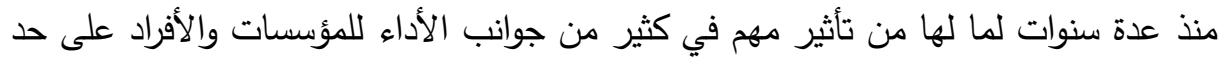
سواء. وهناك العديد من المفاهيم لتكنولوجيا المعلومات. الحوسبة الخضراء، أو تقنية المعلومات الخضراء، أو استدامة تقنيـة معلومـات الحواسيب تشير إلى الحوسبة أو تقنية المعلومات المستدامة بيئيا. في مقالة تسخير تقنية المعلومات الخضراء: مبادئ وممارسات يعرف (2008) Murugesan, S, حقل الحوسبة الخضراء بـانه "دراسة وممارسة تصميم، وتصنيع، واستخدام، والتخلص من الحواسيب، والخوادم، والأنظمة الفرعيـة المرافقة -

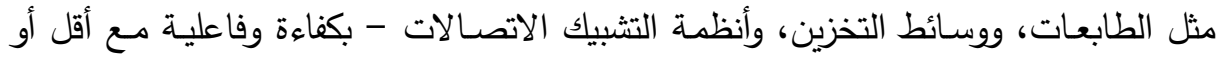
لا تأثير على البيئة. ويمكن تعريفها أيضا بـانها الدراسة والممارسة المتمثلة في تصميم

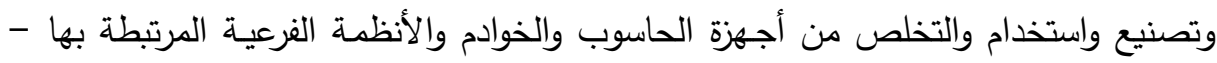

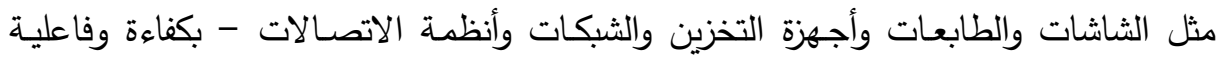

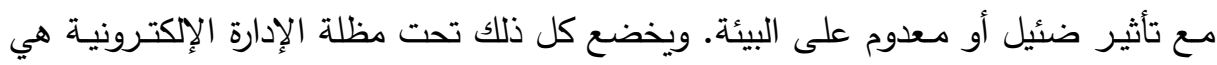

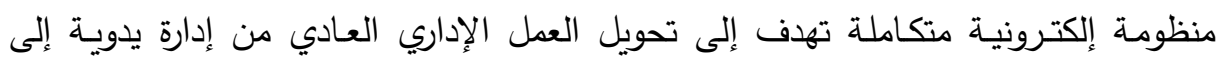
إدارة باستخدام الحاسب وذلك بـالاعتمـاد على نظم معلومـاتيـة قويـة تسـاعد في اتخاذ القرار الإداري بأسرع وقت وباقل التكاليف.

اهتم الفكر الإداري التنظيمي بموضوع الأداء الوظيفي نظرا لارتباطه بكفاءة وفاعلية

المنظمـات في تحقيق أهدافها والوصول إلى مـا تصبو إليه من رؤى وأهداف وقيم جوهريـة.

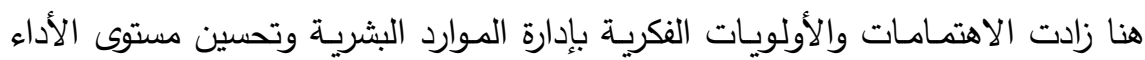

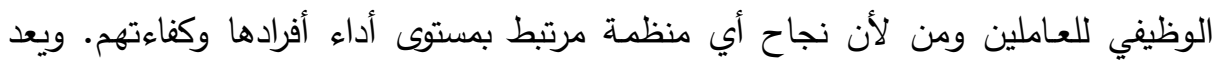

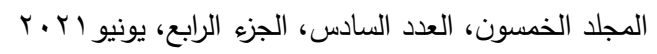


الأداء الوظيفي من الموضوعات التي هي محل اهتمام الباحثين، إذ أنه يعد الوسيلة الوحيدة لتحقيق أهداف العمل والعامل بـالمنظمـات، فهو تفاعل بين رغبة الفرد وقدرته لإنجاز المهام

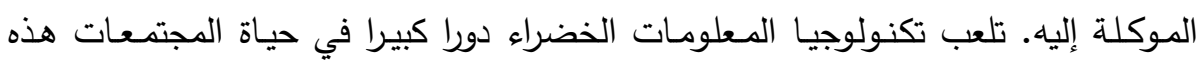
الأيام سواء أكان ذلك على مستوى الأفراد والجماعات ، أم على مستوى المنظمات

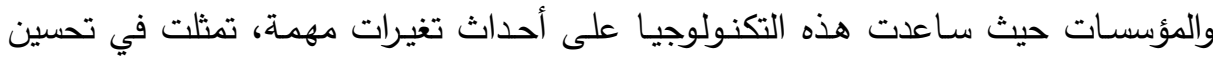

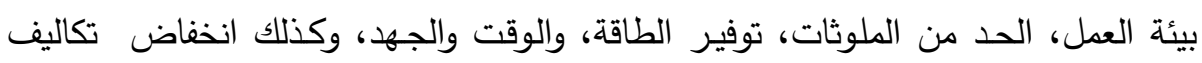

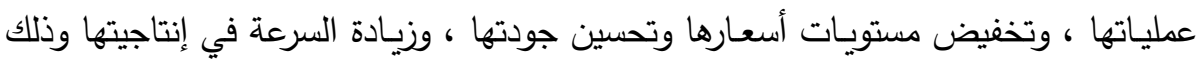

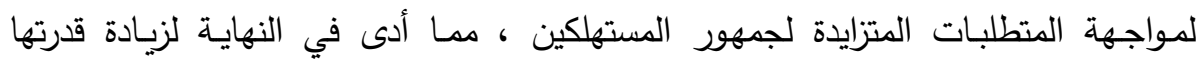

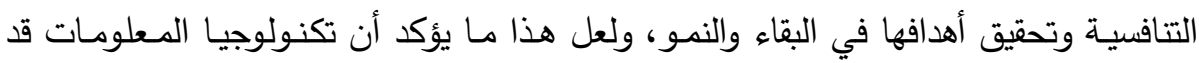
غدت مطلبا أساسيا وليس ترفيهيا للإدارات الباحثة عن الكفاءة والفاعلية في أداء وظائفها •وينظر الى الأداء الوظيفي على أنه القدرة على خلق وإيجاد الأفكار الجديدة القابلة للتطبيق

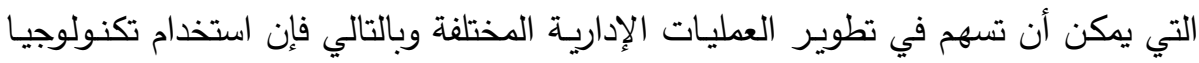

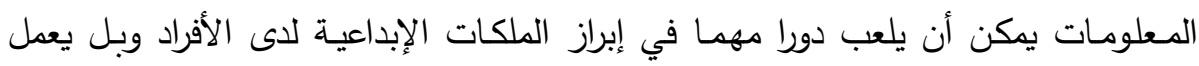

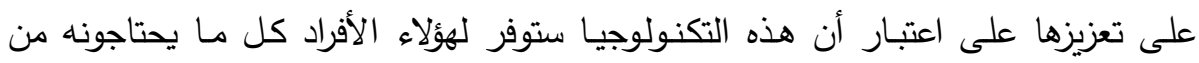

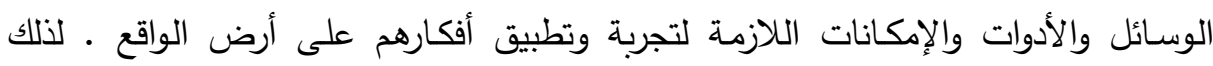
فهناك مبررات ودوافع قويـة لإدخال التكنولوجيا.

\section{همطلحايت التوراسة}

تكنـولوجيـا المسلومـات الخضراء :(متغير مستقل): يعد مصطلح تكنولوجيا المعلومات الاتصـالات الخضراء "Green ICT" هو المصطلح الأكثر رواجا بين المتخصصين والمصنعين والمحللين ومقدمي الخدمات. ويشير المصطلح إلى كافة التقنيات التي تساعد التين

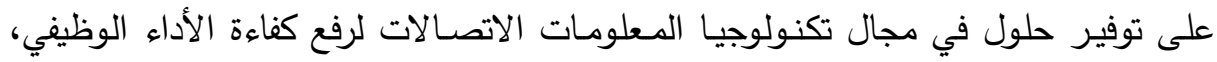
وتوفير الطاقة. 
مجتمع المسعومـات: هو المجتمع الذي يكون فيه لصناعة ونشر واستخدام المعلومـات الأثر الكبير في مختلف النواحي سواء الاقتصـاديـة، أو الاجتمـاعيـة، أو السياسيـة، أو العسكريـة.

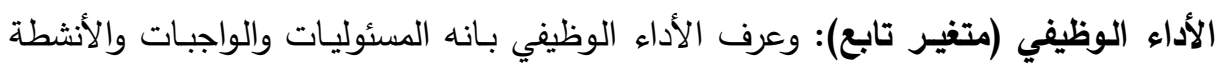

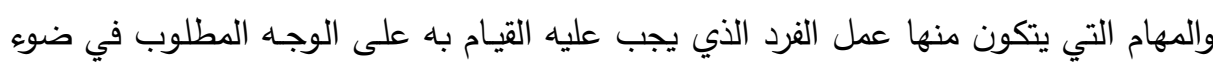
معدلات قدرة العامل الكفه الددرب القيام بها. بناء قرات العاملين: بناء القدرات أو تطوير القدرات هي العملية التي يحصل بها الأفراد

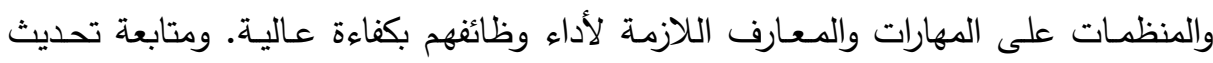
التتميـة.

\section{إلجراءاهي المهنه}

منهج الدراسة: سعيا نحو تحقيق أهداف الدارسة واختبار فروضها، اعتمد الباحثون في إجراء هذه الدراسة على الأسلوب الوصفي التحليلي الكمي، والذي يقوم على وصف، وتحليل

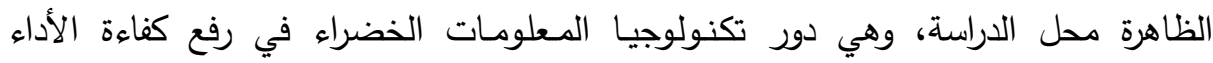
الوظيفي للعاملين بالدولة، وسوف يتم ذلك من خلال جمع البيانات المتعلقة بموضوع الدراسة، وذلك بتصميم قائمة استقصـاء واحدة تغطي الجوانب المتعلقة بمتغيرات الدراسة،

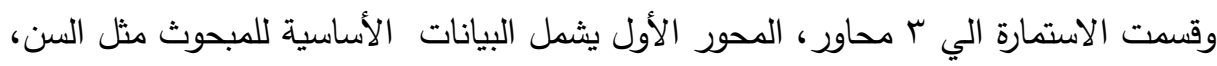
النوع، الخبرة، المؤهل. المحور الثاني يشمل المتغير المستقل " تكنولوجيا المعلومات الخضراء" الذهاء والذي يتضمن (0) ابعاد وكل بعد يشمل (†) عبارات، وأما المحور الثالث يشمل المتغير يتملير التابع "الاداء الوظيفي" والذي يتضمن (0) ابعاد وكل بعد يشمل (0) عبارات، وبذلك يكون

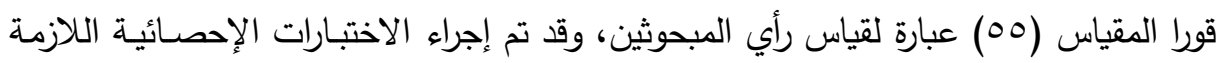
للإجابة على فروض الدراسة، ومن ثم تحليل النتائج بما يخدم أهداف الدراسة. 


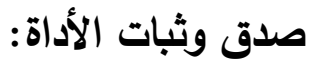

الصدق الظاهرى: وقد تم حساب صدق الاستبيان باستخدام الصدق الظاهري Virtual validity للقيام بتحكيمه، وذلك بعد أن أطلع هؤلاء المحكمون على عنوان الألى على الدانة، وتساؤلاتها، وأهدافها لإبداء آرائهم وملاحظاتهم حول الاستبيان وفقراته من حيث مدى ملائمة الفق ا رت لموضوع الدراسة، وصدقها فى الكشف عن المعلومات المستهدفة للدراسة، وكذلك من حيث ترابط كل فقرة بالدحور التى تتدرج تحته، ومدى وضوح الفقرة وسلامة صياغتها، وذلك بتعديل الفقرات أو

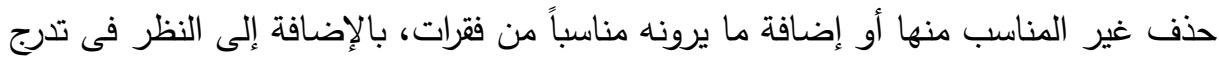
الاستبيان، وغير ذلك مما يراه الخبراء مناسباً (Oluwa Tayo, 2012, p.392) . الصدق الذاتي: يتم التعرف عليه عند معامل ثبات المقياس وذلك لما بين صدق المقياس وثباته صلة وثيقة حيث يحسب الصدق الذاتي بحساب الجذر التربيعي لمعامل الثبات

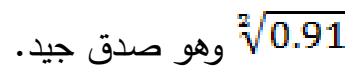

الثبات: ويعنى مدى إنساق المقياس مع نفسه في قياس أي بعد بنفسه أى مدى إستقرار

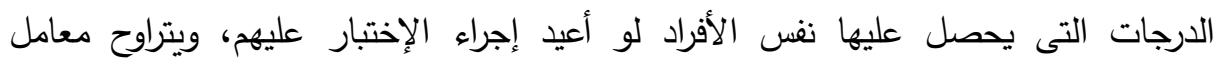

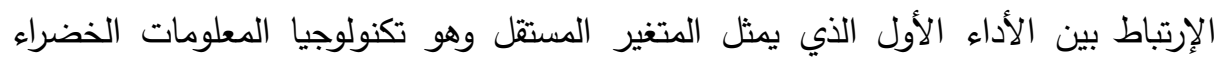

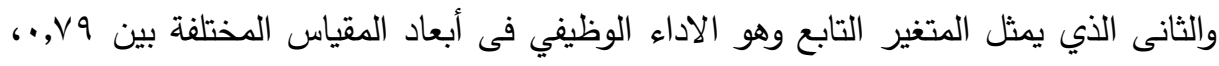

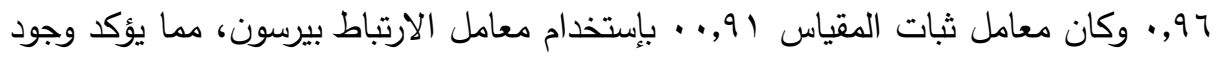
علاقة ارتباط قويه بين المتغيرات.

وصف عينة البحث: يشمل مجتمع الدراسة جميع العاملين بوزارة الاتصـالات وتكنولوجيا

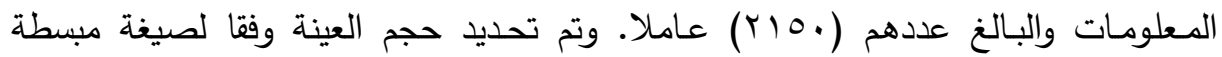
أقترحها (Yamane, 1967). وقد تم اختيار عينة عشوائيـة بسيطة من مجتمـع الدراسة الذي لماتي 


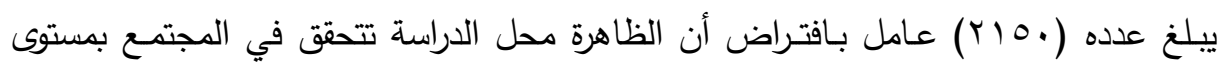
دقة 0\% وبالتطبيق في معادلة حجم العينة فأن حجم العينة يتم تحديده كما يلي:

$$
\mathrm{n}=\frac{N}{1+N d^{2}}
$$

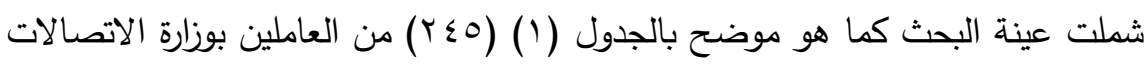

وتكنولوجيا المعلومات من مختلف الفئات العمرية، والدرجة الوظيفية، والعمر ، والخبرة.

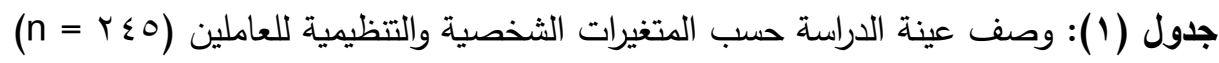

\begin{tabular}{|c|c|c|c|}
\hline النسبة \% & التكرار & $(n=245)$ & وصف \\
\hline $1 \wedge, \wedge$ & 46 & مدير & \multirow{4}{*}{ ل للرجة الوظيفية } \\
\hline$r \leqslant, 1$ & 59 & نائب مدير & \\
\hline$r 7,0$ & 65 & مشرف & \\
\hline$r \cdot, \tau$ & 75 & اخري & \\
\hline$r 7,0$ & 65 & اقل من ·r سنة & \multirow{4}{*}{ العمر } \\
\hline$Y_{0, V}$ & 63 & من اب الى •؛ سنة & \\
\hline$r \cdot, r$ & 74 & من إ الى .0 سنة & \\
\hline $1 V, 7$ & 43 & أكثر من •0 سنة & \\
\hline $79, \varepsilon$ & 170 & ذكر & \multirow{2}{*}{ النوع } \\
\hline$r \cdot, 7$ & 75 & انثي & \\
\hline$r, r$ & 52 & اقل من ه سنوات & \multirow{4}{*}{ سنوات الخبرة } \\
\hline$r \mu, r$ & 57 & من 7 الى • ( سنوات & \\
\hline$r, \Lambda$ & 78 & من 11 اللى 10 سنوات & \\
\hline$r \mu, V$ & 58 & من 17 الي · r سنوات & \\
\hline$r, r$ & 52 & ثانوي & \multirow{3}{*}{ المؤهل العلمي } \\
\hline 01,9 & 127 & جامعي & \\
\hline$r 7,9$ & 66 & فوق الجامعي & \\
\hline
\end{tabular}

ويتضح من الجدول رقم (1) ان نسبه ^,^/\% من إجمالي المجتهع العاملين بدرجة

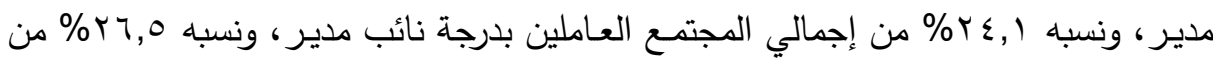

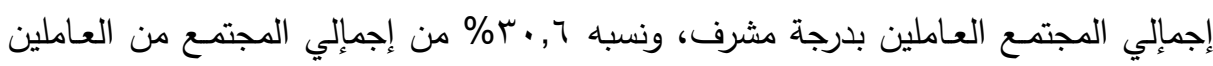

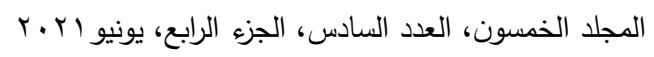




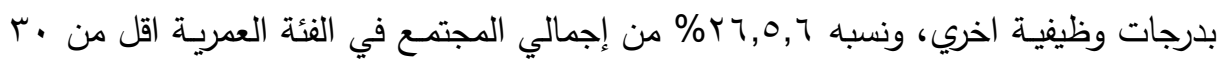

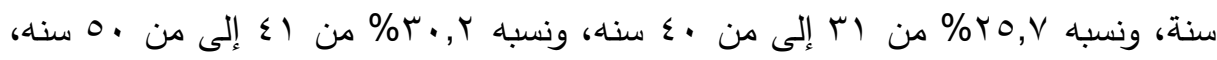

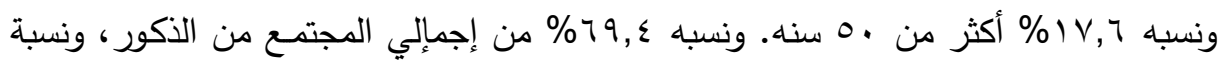

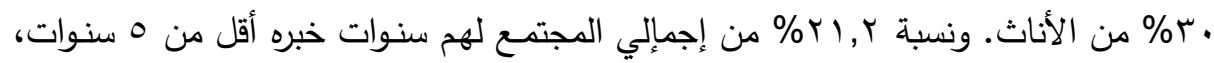

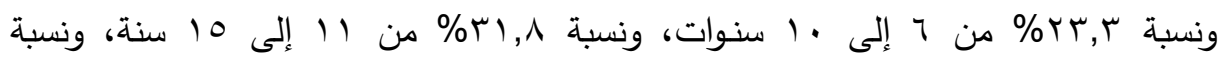

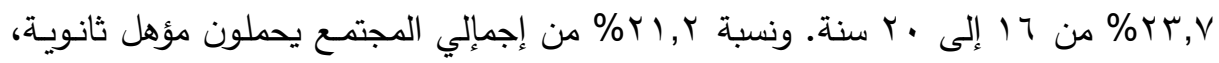

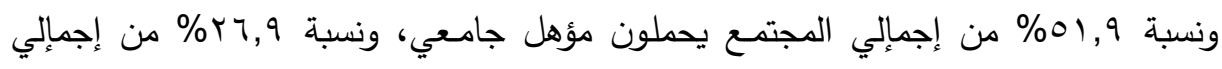
المجتمع يحملون مؤهل فوق الجامعي.

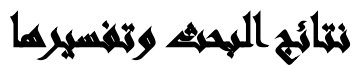

جدول (r): معاملات ارتباط بين ابعاد تكنولوجيا المعلومات الخضراء والأداء الوظيفي n=245 معاملات معنويه عند مستوي معنويه 1\%

\begin{tabular}{|c|c|c|c|c|c|c|}
\hline الكنولوجيات & ومعدات & الالعنصرل & الشبكات & برمجيات & تكنولوجيا & الأبعاد \\
\hline "AVI. & "N17. & "Norr. & "* ^९า. & $" 7.1$. & "Av1. & ومهارات العاملين \\
\hline "107. & " $\wedge \vee \varepsilon$. & "*זт. & "Атی. & "“711. & "q人r. & السرعة في إنجاز \\
\hline "97r. & 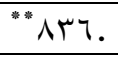 & $" \vee \vee 9 .$. & "V१r. & "0 $0 \leqslant r$. & "VRT. & جودة العمل \\
\hline "Nזะ. & "VAl. & " $\vee$ ४ & $" \wedge \wedge \vee$. & & & الألة في إنجاز \\
\hline "^१९. & "*ト. & " $\vee \vee 9$. & $" * 9.1$. & "VIY. & $" q 1 \mathrm{~V}$. & الموثوقية \\
\hline "qvi. & "v^r. & "* & "ᄉ & $" 011$. & "Атт. & المعرفة بالعمل \\
\hline "qAr. & "*ґᄉ. & "v9r. & "* $\wedge \vee \wedge$. & $" 7 \wedge \Lambda$. & "qाr. & الأداء الوظيفي \\
\hline
\end{tabular}


ويتضح من جدول (r) ما يلي: وجود ارتباط طردي قوي بين (ثورة تكنولوجيا المعلومات) كأحد ابعاد تكنولوجيا المعلومات الخضراء و (السرعة في إنجاز الأعمال) كأحد ابعاد الأداء

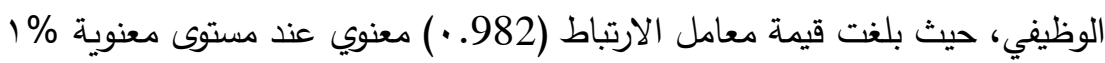

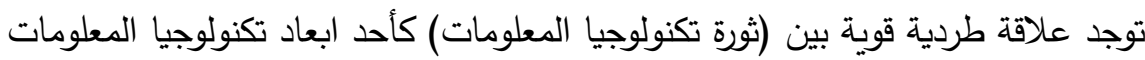

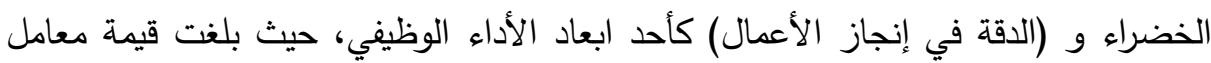

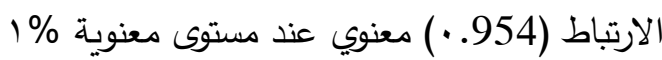

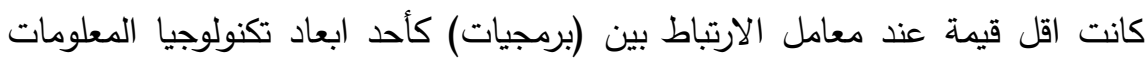

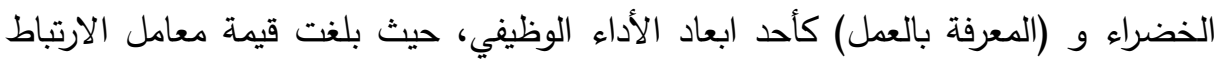

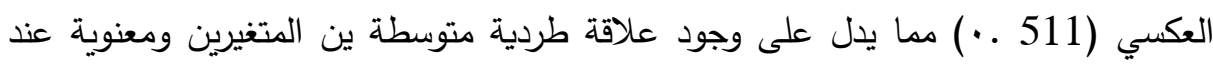
مستوي معنوية \% 1. مما سيق يتضح انه توجد علاقة ذات دلالة إحصائية لأبعاد تكنولوجيا المعلومات الخضراء (ثورة تكنولوجيا المعلومات - أجهزة ومعدات - برمجيات - الثبكات - الاتصال والعنصر البشري) على ابعاد الأداء الوظيفي للعاملين بالوزارة محل الدراسة. الفرض الفرعي الأول من الفرض الرئيسي للدراسة: يوجد أثر ذو دلالة إحصائية لأبعاد تكنولوجيا المعلومات الخضراء (ثورة تكنولوجيا المعلومات - أجهزة ومعدات - برمجيات - الثبكات - الاتصال والعنصر البشري) على سرعة اداء العاملين. 
جدول (ץ): تقديرات نموذج الانحدار المتدرج على سرعة اداء العاملين n=245

\begin{tabular}{|c|c|c|c|c|c|c|}
\hline \multicolumn{4}{|c|}{ التقديرات } & \multirow{2}{*}{ في المستقلة المتيرات } & \multirow{2}{*}{$\begin{array}{c}F \\
\text { (.sig) }\end{array}$} & \multirow{2}{*}{$\begin{array}{c}\text { التحديد } \\
\text { R2 } \\
\end{array}$} \\
\hline .Sig & $\mathbf{T}$ & B & & & & \\
\hline . & ה אזד & $\cdot, \leqslant 70$ & (Constant) & $\times 7.31$ & צ & \multirow{6}{*}{$\cdot, \wedge \vee q$} \\
\hline - & $\Lambda, q \leqslant 1$ & $\cdot, \Sigma 7 V$ & ثورة تكنولوجيا & $\times 14.91$ & - & \\
\hline - & $7, \cdot 7 Y$ & •, Y१ & برمجيات & & & \\
\hline . & $\{, 7 \pi$ & $\cdot, r \leqslant 1$ & الثبكات & & & \\
\hline - & דיז,r & - rvq & الاتصال والعنصر & & & \\
\hline . & $V, 01 Y$ & . ז ז & أجهزة ومعدات & & & \\
\hline
\end{tabular}

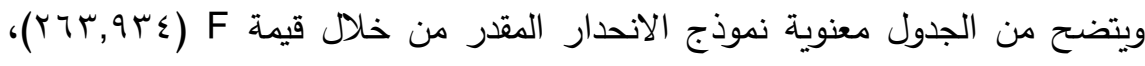

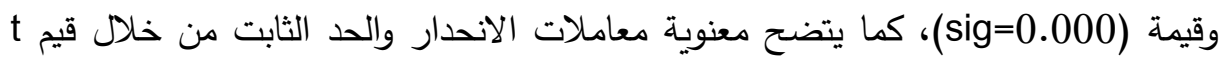
وقيم . sig عند مستوي معنوية 0\% وبلغت قيمة معامل التحديد (AV9, •) مما يدل على ان المتغيرات المستقلة تفسر

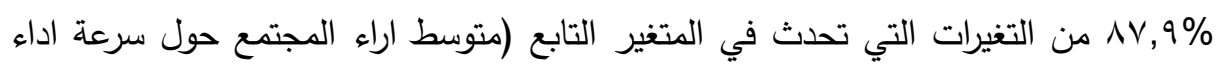
(العاملين). مما سبق يتضح صحة الفرض الأول من الفرض الرئيسي الأول للاراسة: يوجد أثر ذو دلالة

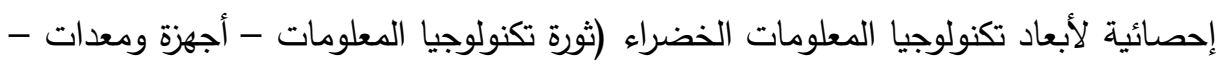
برمجيات - الثبكات - الاتصال والعنصر البشري) على سرعة اداء العاملين.

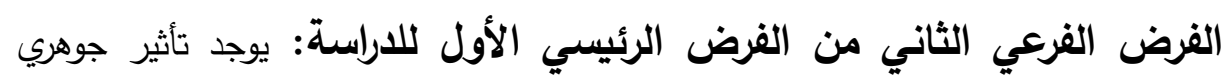

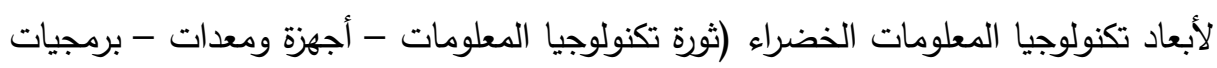
- الثبكات - الاتصال والعنصر البشري) جودة أداء العاملين في الجهة محل الدراسة. 


$$
\begin{aligned}
& \text { مجلة العلوم البيئية } \\
& \text { معهد الدراسات والبحوث البيئية - جامعة عين شمس لبس } \\
& \text { وليد محمد عبد الحفيظ وآخرون }
\end{aligned}
$$

\begin{tabular}{|c|c|c|c|c|c|c|}
\hline \multicolumn{4}{|c|}{ التقديرات } & \multirow{2}{*}{ المستقلة في النموذات } & \multirow{2}{*}{$\begin{array}{c}F \\
\text { (.sig) } \\
\end{array}$} & \multirow{2}{*}{$\begin{array}{c}\text { معامل } \\
\text { R2 } \\
\text { R2 } \\
\end{array}$} \\
\hline .Sig & $\mathbf{T}$ & B & & & & \\
\hline$\cdot, \cdots$ & $1, \wedge \leqslant V$ & • & (Constant) & ثورة تكنولوجيا & $V \leq 7, \cdot Y$ & \multirow{6}{*}{$\cdot, 9 \leqslant 1$} \\
\hline . & $1 \Lambda, r T \leq$ & $\cdot, \wedge \varepsilon$ & ثورة تكنولوجيا & أجهزة ومعدات & . & \\
\hline . & $\varepsilon, 790$ & $\cdot, 191$ & برمجيات & برمجيات & & \\
\hline . & $7, r \leq q$ & r., ror & الشبكات & الثبكات & & \\
\hline . & $\Lambda, r \circ \Lambda$ & •, rq & والعنصر البشري الاتصال & والعنصر البشري & & \\
\hline . & $\Lambda, V Y T$ & $\cdot,\{71$ & أجهزة ومعدات & & & \\
\hline
\end{tabular}

ويتضح من الجدول (ع) معنوية نموذج الانحدار المقدر من خلال قيمة f f(746.020)،

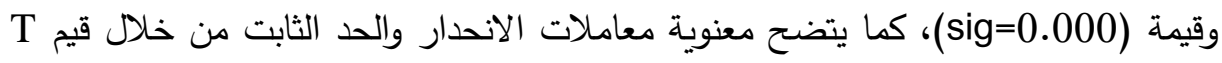

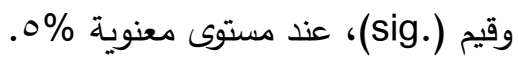

ويتضح من جدول (ع) ان اهم ابعاد تكنولوجيا المعلومات الخضراء التي تؤثر في جودة أداء العاملين في الوزارة محل الدراسة هي: ثورة تكنولوجيا المعلومات، برمجيات، الثبكات

$$
\text { الاتصال والعنصر البشري، أجهزة ومعدات) }
$$

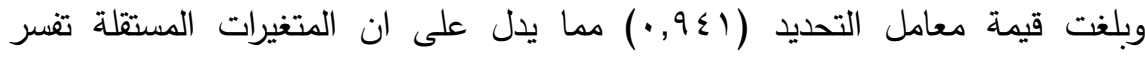
\% 1 , 9 من التغيرات التي تحدث في المتغير التابع (متوسط اراء المجتمع حول جودة أداء

$$
\text { (العاملين). }
$$

مما سبق يتضح صحة الفرض الفرعي الثاني من الفرض الرئيسي الأول للاراسة: يوجد

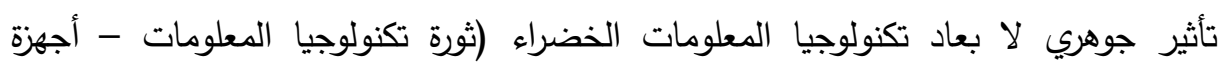

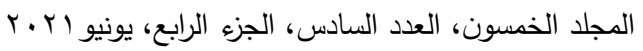

$$
\begin{aligned}
& \text { الترقيم الدولي 0826- ISSN 1110 }
\end{aligned}
$$


ومعدات - برمجيات - الشبكات - الاتصال والعنصر البشري) على جودة أداء العاملين في الجهة محل الدراسة.

الفرض الفرعي الثالث من الفرض الرئيسي الأول للاراسة: يوجد تأثير جوهري

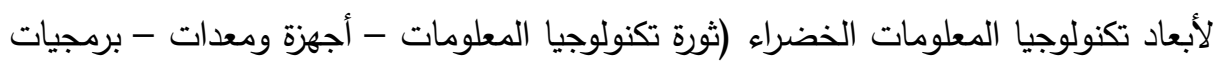
- الثبكات - الاتصال والعنصر البشري) على المعرفة بالعمل في الجهة محل الدراسة.

\begin{tabular}{|c|c|c|c|c|c|c|}
\hline \multicolumn{4}{|c|}{ التقديرات } & \multirow{2}{*}{ المتغيرات المستقلة في } & \multirow{2}{*}{$\frac{F}{\text { (.sig) }}$} & \multirow{2}{*}{$\begin{array}{l}\text { معداميد } \\
\text { R2 }\end{array}$} \\
\hline Sig & $T$ & b & & & & \\
\hline$\cdot$ & $\varepsilon, \vee \wedge O$ & $\cdot, \mathrm{TAV}$ & (Constant) & البرمجيات & $r \varepsilon 0, \varepsilon r v$ & \multirow{3}{*}{., $\vee 91$} \\
\hline . & $T, Y Y I$ & $\cdot, \Gamma / 9$ & برمجيات & الثبكات & $\cdot$ & \\
\hline . & IV, rov &.,$T \leqslant \tau$ & الثبكات & & & \\
\hline
\end{tabular}

F ويضضح من الجدول (0) معنوية نموذج الانحدار المقدر من خلال قيمات

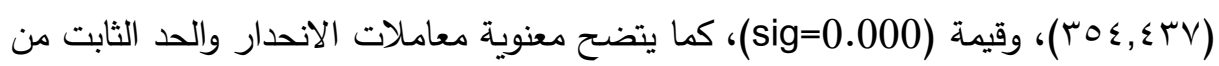

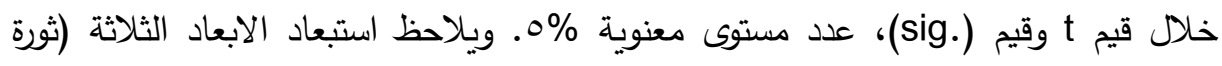
تكنولوجيا المعلومات - أجهزة ومعدات - الاتصال والعنصر البشري) لعدم معنويتهم.

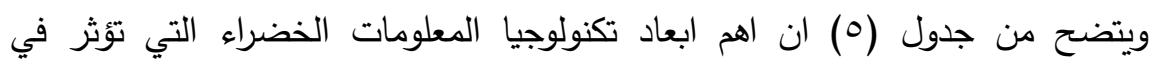
المعرفة بالعمل في العاملين بالوزارة هي: (برمجيات، الثبكات).

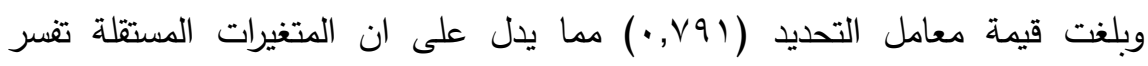

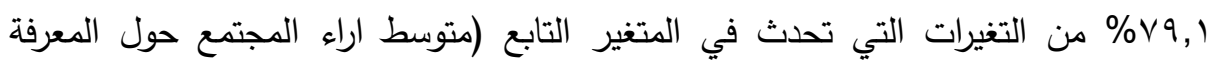
بالعمل). مما سبق يتضح صحة الفرض الفرعي الثالث من الفرض الرئيسي الأول للاراسة: يوجد أثر الثرات

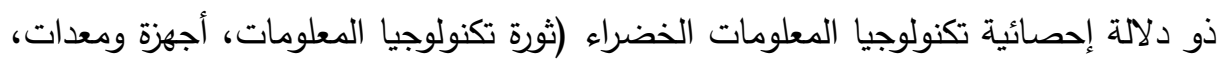
برمجيات، الثبكات، الاتصال والعنصر البشري) على العرفة بالعمل 
الفرض الفرعي الرابع من الفرض الرئيسي للاراسة: يوجد تأثير جوهري لأبعاد

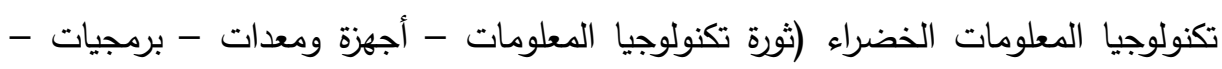

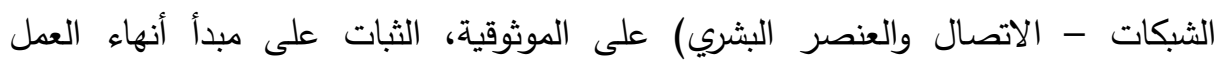

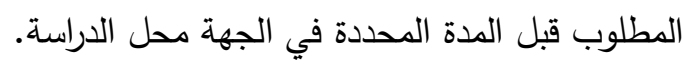
جدول (؟): تقديرات نماذج الانحدار المتدرج على الموثوقية: مبدأ أنهاء العمل المطلوب قبل n=24 المدة المحددة

\begin{tabular}{|c|c|c|c|c|c|c|}
\hline \multicolumn{4}{|c|}{ التقديرات } & \multirow{2}{*}{ المستقلة في النموذ جي } & \multirow{2}{*}{$\frac{F}{\text { (.sig) }}$} & \multirow{2}{*}{$\begin{array}{l}\text { التحديد } \\
\text { R2 }\end{array}$} \\
\hline .Sig & $\mathbf{T}$ & B & & & & \\
\hline - & $\varepsilon, \wedge \varepsilon \vee$ & $\cdot, r 09$ & (Constant) & ثورة تكنولوجيا & $1.79, \wedge 91$ & \multirow{5}{*}{$\cdot, 94 \wedge$} \\
\hline - & $r 0,1 \cdot r$ & $\cdot, \vee \vee १ \wedge$ & ثورة تكنولوجيا & برمجيات & - & \\
\hline - & $\varepsilon, 7) \pi$ & $\cdot, 11 \leq$ & برمجيات & الاتصال والعنصر & & \\
\hline - & $0, \varepsilon \Gamma \wedge$ & $\cdot, 1.9$ & الاتصال والعنصر & أجهزة ومعدات & & \\
\hline . & $7, \wedge 9 \leq$ & $\cdot, r \leqslant V$ & أجهزة ومعدات & & & \\
\hline
\end{tabular}

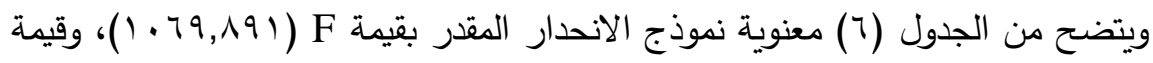

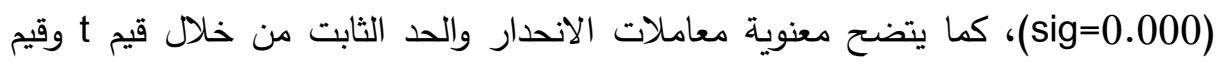
0\% م. ويلاحظ استبعاد الابعاد الأربعة (الثبكات) لعدم معنويتها.

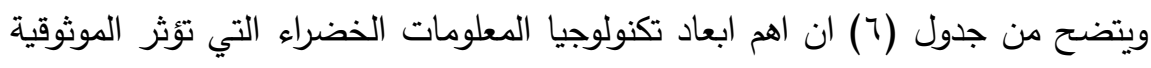
في العاملين بالوزارة: (ثورة تكنولوجيا المعلومات، برمجيات، الاتصال والعنصر البشري، أجهزة ومعدات).

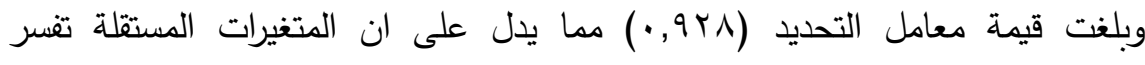
1, ^9\% من التغيرات التي تحدث في المتغير التابع (متوسط اراء المجتمع حول الموثوقية).

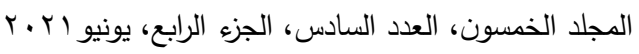

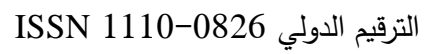


مما سبق يتضح صحة الفرض الفرعي الرابع من الفرض الرئيسي الأول للدراسة: يوجد أثر

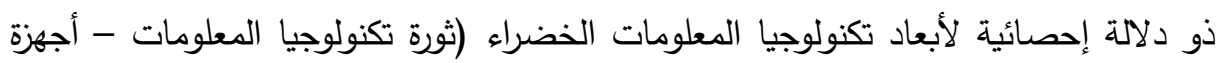
ومعدات - برمجيات - الشبكات - الاتصال والعنصر البشري) على الموثوقية.

\section{الإلمصاء اللوصهنه}

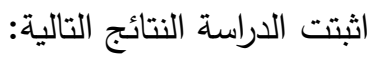
• ارتفاع متوسط اراء الاناث حول البعد (ثورة تكنولوجيا المعلومات) كأحد ابعاد تكنولوجيا

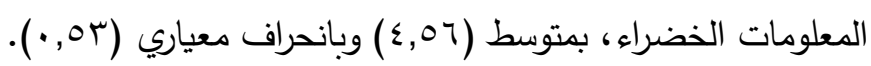

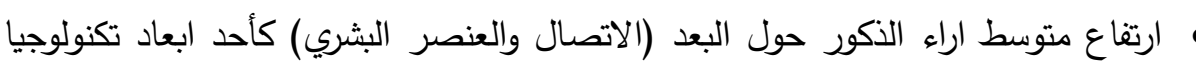

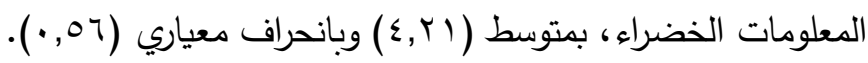

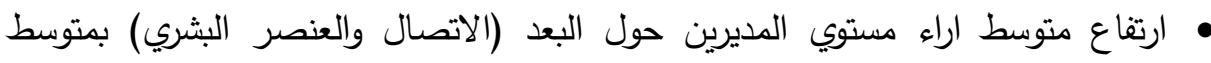

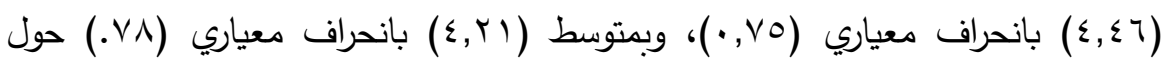
البعد أجهزة ومعدات. أحسات • ارتفاع متوسط اراء مجتمع الدراسة حول البعد (ثورة تكنولوجيا المعلومات) بمتوسط

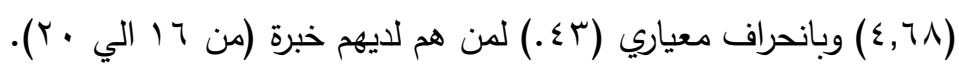

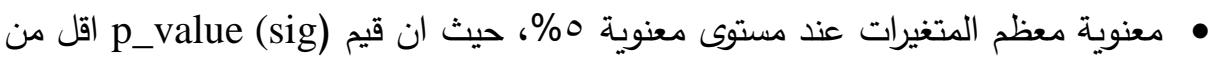

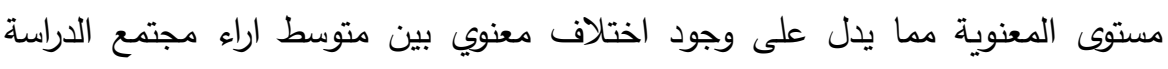
حسب النوع، والدرجة الوظيفية، مدة الخبرة. مما سبق يتضح انه توجد فروق ذات دلالة إحصائية في إجابات مجتمع الدراسة بالوزارة

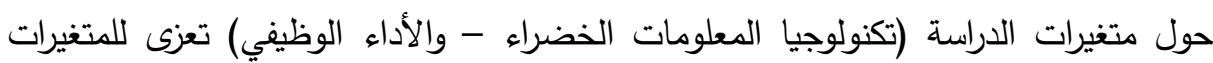
الثخصية والتنظيمية المتمثلة في (النوع، والدرجة الوظيفية، مدة الخبرة). وتتفق نتائج الدراسة الحالية مع نتائج مجموعة من الدراسات، كثفت عن وجود فروق الكانه

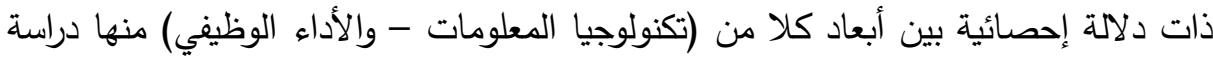
600 


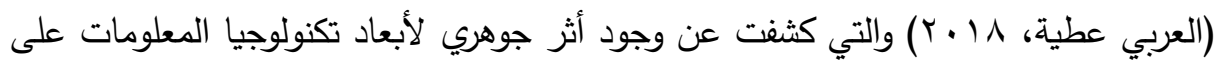

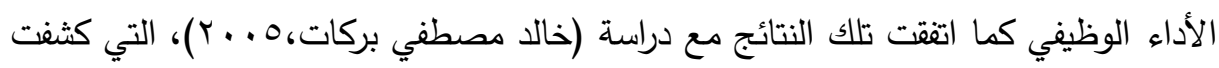
عن وجود أثر جوهري لاستخدام تكنولوجيا المعلومات على تحسين الأداء المؤسسي للهيئات

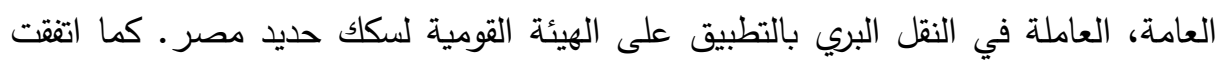

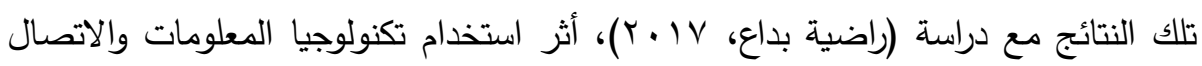
على الأداء الوظيفي في المؤسسات الصغيرة والمتوسطة كلية العلوم الاقتصادية والعلوم التجارية وعلوم التسيير جامعة ورقلة، الجزائر .

\section{تمبياهت اللهمثه}

• متابعة ومواكبة التطورات العالمية للتكنولوجيا وتتفيذ اعمالها وتطبيقها من خلال تلك التقنيات في المنظمة مما يؤدي الي رفع كفاءة الأداء الوظيفي.

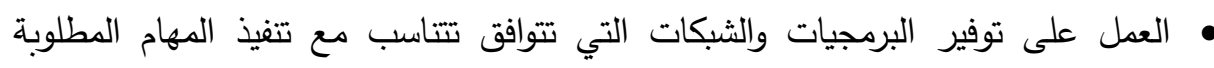
بسهولة وتطبيقها عمليا على جميع الادارات. العمل على تطوير العنصر البشري بصفة مستمرة من خلال التدريب والتوعية والتحفيز والتأهيل. • العمل على تطوير وتوفير الاجهزة والمعدات التكنولوجية المستخدمة بما يتتاسب مع البيئة والاعمال المطلوب إنجازها وصيانتها وتدريب العاملين عليها.

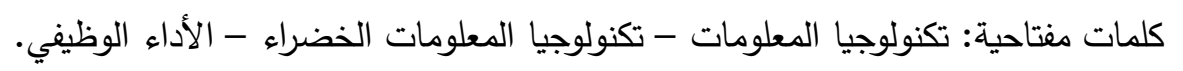

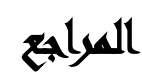

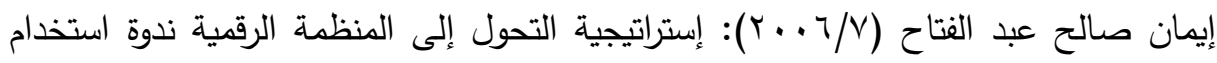

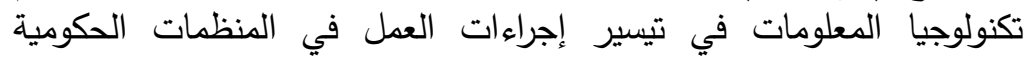

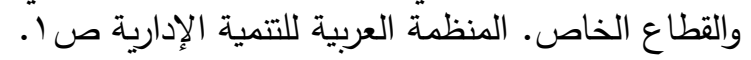

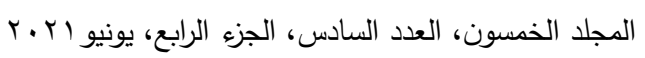

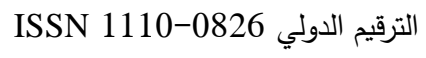




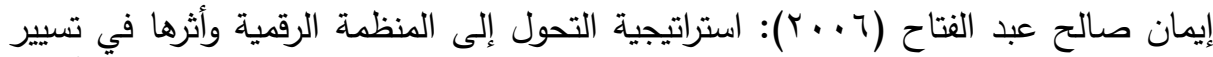

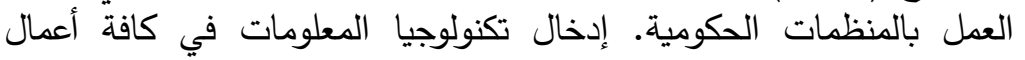

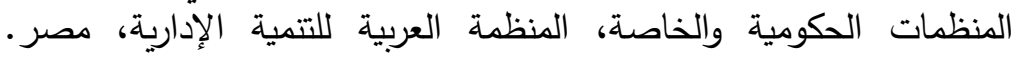

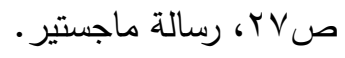

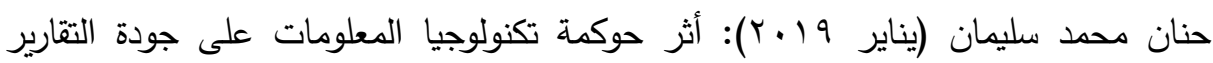

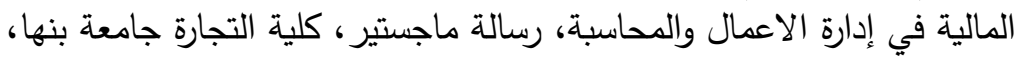

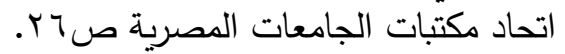

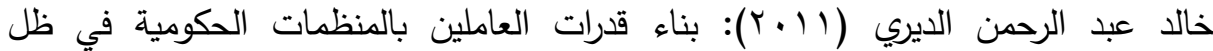
تكنولوجيا المعلومات، وزارة الصحة والتعاون الدولي، كلية التجارة، جامعة فالفيات

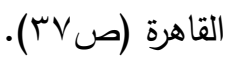

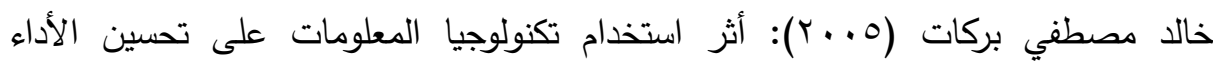

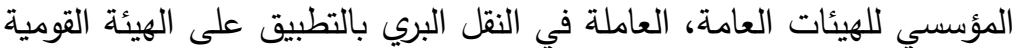

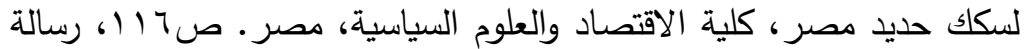
دكتوراة.

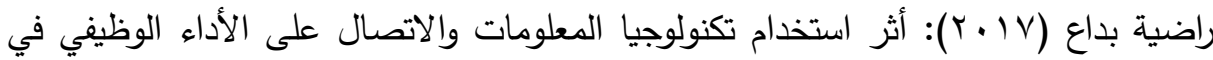

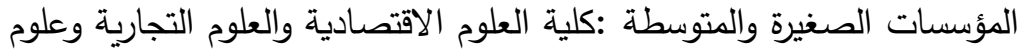
التسيير جامعة ورقلة، الجزائر ، رسالة ماجستير .

سعيد على الثوف: مفهوم الأداء الوظيفي وأهيته البالغة في تحقيق أهداف العمل فهو الوسيلة

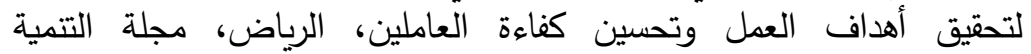

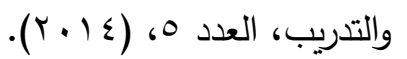

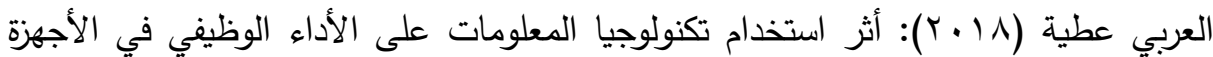

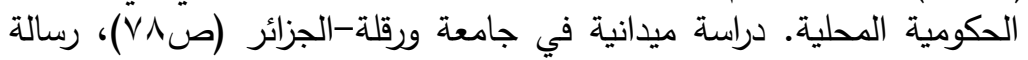
دكتوراة.

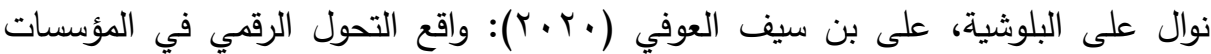

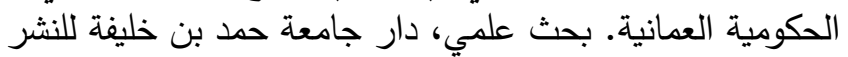

Journal of Information Studies \& Téchnology (JIS\&T), Volume 2020, Issue 1 . 


$$
\begin{aligned}
& \text { مجلة العلوم البيئية } \\
& \text { معهد الدراسات والبحوث البيئية - جامعة عين شمس لبن } \\
& \text { وليد محمد عبد الحفيظ وآخرون }
\end{aligned}
$$

Barbara, A. (2012): Implications of the carbon price on business. IT and the Internal audit department. available at www.sustainable/business/consulting.com.au

Gupta, R. (2000): Optimum utilization of IT in public administration, the Indian Journal of public administration, XLV. 1. 3

Huang, C.: The Effect of Investment in Information Technology on the Performance of Firms in the Rubber Industry. International Journal of Management, Vol. 24, No. 3, (2007) pp.(463619).

James A., Senn (2000): Information Technology in Business Principles Practices, and Opportunities (NJ: Prentice Hall. Upper Saddle river) P.23.

Mayfield, J., and Milton M.: Influence on motivation language a two levels model innovation on work performance and job satisfaction, competitiveness review: An international business journal, Vol.20 No.5 (2010).

Yamane, Taro (1967), Statistics, An Introductory Analysis, $2^{\text {nd }}$ Ed., New York: Harper and Row, p.286.

$$
\begin{gathered}
\text { المجلد الخمسون، العدد السادس، الجزء الرابع، يونيو I ب الترقيم الدولي 0826-110 } \\
\text { ISSN 110 }
\end{gathered}
$$




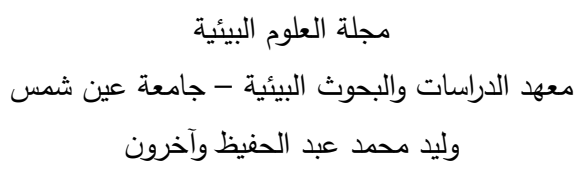

\title{
EFFECT OF GREEN INFORMATION TECHNOLOGY ON JOB PERFORMANCE A FIELD STUDY ON THE MINISTRY OF COMMUNICATION AND INFORMATION TECHNOLOGY
}

\author{
Waleed M. Abdel Hafiz(1); Mamdouh A. Refaai( ${ }^{(2)}$ \\ Mohamed H. Abdul Aziz ${ }^{(3)}$ and Ekram M. A. Gomaa ${ }^{(2)}$ \\ 1) Ministry of Communication and Information Technology 2) Faculty \\ of Commerce, Ain Shams University 3) Faculty of Computer \& info. \\ Sciences, Ain Shams University
}

\begin{abstract}
The current study aims to know the effect of green information technology on raising the efficiency of the employees of the Ministry of Communications and Information Technology. Where information technology was represented by the independent variable, which was measured through several items, namely, Information technology revolution, green information technology, hardware and equipment, software, networks, communication and the human element. As for raising the efficiency of the employees' performance, it is represented by the dependent variable, which was measured through several items, namely. Raising the efficiency and skills of workers, speed in completing work, quality of work, accuracy in completing work without errors, reliability, and consistency on the principle of completing the required work before the specified period. Knowledge of work Full mastery of the skills and duties required at work. The research problem was identified through a group of questions: Is there a difference between IT and green IT? Is there an impactful relationship of green 604

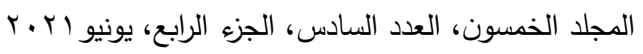

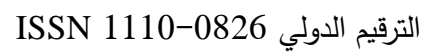




$$
\begin{aligned}
& \text { مجلة العلوم البيئية } \\
& \text { معهد الدراسات والبحوث البيئية - جامعة عين شمس لبس } \\
& \text { وليد محمد عبد الحفيظ وآخرون }
\end{aligned}
$$

information technology on employee job performance? What are the requirements and results of using green information technology in raising the efficiency of the job performance of state employees? To what extent has the experience of the state's administrative apparatus in using green information technology? What are the indications that confirm the actual application of green technology when using technology in public administration for optimal use? How important is the application of green technology to the environment and society as a whole? In light of these questions, a set of hypotheses have been formulated to diagnose the reality of the impact of green information technology on the performance of workers in the Ministry of Communications and Information Technology, as it is the body responsible for modernizing technology in the country. The researcher relied on obtaining the data on the exploratory study. A questionnaire form was distributed to a randomly selected sample of employees in the ministry, which amounted to (245 employees) at the level of departments and units out of the total employees and was analysed using the (SPSS) program.

The study reached a set of preliminary results, which is the acceptance of research hypotheses that confirm the existence of a relationship and the impact of green information technology on improving the performance of employees. In addition to a set of results in which a set of recommendations were formulated in light of the ability to employ information technology in the direction that serves the ministry and employees.

$$
\begin{gathered}
\text { المجلد الخمسون، العدد السادس، الجزء الرابع، يونيو I r الترقيم الدولي 0826-110 } \\
\text { ISSN 110 }
\end{gathered}
$$

